\title{
Optimal Taxation and the Tradeoff Between Efficiency and Redistribution
}

\author{
GEORGE ECONOMIDES
}

Athens University of Economics and Business and CESifo

\author{
ANASTASIOS RIZOS \\ Athens University of Economics and Business and Economic Research Division, \\ Alpha Bank *
}

\begin{abstract}
This paper studies the aggregate and distributional implications of introducing consumption taxes into an otherwise deterministic version of the standard neoclassical growth model with income taxes only and heterogeneity across agents. In particular, the economic agents differ among each other with respect to whether they are allowed to save (in physical capital) or not. Policy is optimally chosen by a benevolent Ramsey government. The main theoretical finding comes to confirm the widespread belief that the introduction of consumption taxes into a model with income taxes only, creates substantial efficiency gains for the economy as whole, but at the cost of higher income inequality. In other words, consumption taxes reduce the progressivity of the tax system, and maybe, from a normative point of view, this result justifies the design of a set of subsidies policies which will aim to outweigh the regressive effects of the otherwise more efficient consumption taxes.
\end{abstract}

Keywords: Ramsey taxation, heterogeneity, efficiency, inequality

JEL Classifications: H21, H23, E62

\section{Introduction}

The literature on optimal taxation typically focuses on income taxes and rules out consumption taxes. For example, Chamley (1986), Judd (1985) and Lucas (1990) assumed that the consumption of goods is untaxed in each period and that there are only taxes on income from savings and labour. However, consumption taxes are a very popular tax policy instrument, in

\footnotetext{
* Corresponding author: Anastasios Rizos, Athens University of Economics and Business, 76 Patission street, Athens 10434, E-mail: rizosanasta@aueb.gr, t.rizos@hotmail.com. We thank Sarantis Kalyvitis, Christos Kotsogiannis, Thomas Moutos, Apostolis Philippopoulos and Vanghelis Vassilatos for discussions and comments. Any errors are ours. The views and opinions expressed herein are those of the author and do not necessarily represent or reflect the views of Alpha Bank.

(C) 2017 George Economides and Anastasios Rizos. Licensed under the Creative Commons Attribution - Noncommercial 3.0 Licence (http://creativecommons.org/licenses/by-nc/3.0/) . Available at http://rofea.org.
} 
the hands of policymakers, and this can be confirmed by their widespread use in most industrialized economies. For instance, according to Table 1 below, average effective consumption tax rates are about $22.1 \%$ in a sample of 25 countries, where data are taken by Eurostat for a ten year period (2002-2010). The estimates regarding average effective consumption tax rates vary considerably across countries. For example, in the aforementioned sample of countries, the average effective consumption tax rates are between 15.1 and 32.7. Furthermore, revenues from consumption taxes represent a significant proportion of total tax revenues. For instance, the average percentage of revenues from consumption taxes over total tax revenues for the same sample is about $33.2 \%$. For a number of countries, such as Cyprus, Latvia, Lithuania, Hungary and Portugal, this percentage is even higher and exceeds $38 \%$.

This popularity of consumption taxes, as a policy instrument in the hands of policymakers, can be explained by the widespread belief, that they are a less distortive policy instrument relative to income taxes and, thus, increase aggregate efficiency (see e.g. Coleman (2000), Correia (2010) and many others). However, consumption taxes are also believed to increase income inequality and, thus, hurt the medium and low income social classes. Motivated by the above, this paper aims to study the role of consumption taxes in a two-period deterministic version of the neoclassical growth model. Following most of the relevant literature, we follow the Ramsey approach to the optimal tax policy problem according to which the government is able to commit to future policies ${ }^{1}$. By allowing the government to choose optimally the tax mix (between income and consumption taxes), we aim to study the tradeoff between efficiency and redistribution.

To capture the distributional implications, we need to distinguish among the various economic agents so as to generate a potential conflict of interests. According to Turnovsky (2000), the most common distinction in the literature that creates a potential conflict of interests is the functional distribution between income going to capital and that going to labour. Thus, we work with a two-period deterministic version of Judd's (1985) neoclassical growth model, in which households differ in capital holdings. In particular, we assume that there are two groups of households, called capitalists and workers, where capital is in the hands of capitalists, while workers, who form the majority in our economy, are not allowed to save2. Moreover, we assume that capitalists are more skilled than workers and, thus, the aggregate labor input is a

\footnotetext{
${ }^{1}$ Following most of the relevant literature, we focus only on the optimal tax setting under commitment and rule out the study of time-consistent fiscal policies (for a review of the literature on time-consistent optimal tax policy with consumption taxes in infinite-horizon models, see e.g. Laczo and Rossi (2014) and Motta and Rossi (2015)).

${ }^{2}$ This has been one of the most commonly used models with heterogeneity in the literature on optimal taxation. See also Lansing (1999), Krusell (2002) and Fowler and Young (2006).
} 
linear function of high-skilled and low-skilled labor, which are supplied by capitalists and workers respectively (as in Hornstein et al. (2005)). This differentiation between high-skilled and low-skilled labor is driven by differences in labor factor productivities. The government is allowed to finance the provision of utility-enhancing public goods by choosing not only the level of government spending but also the mix between income and consumption taxes. All types of taxes are proportional to their own tax base ${ }^{3}$.

Table 1: Consumption Taxes, 2000-2012

\begin{tabular}{|l|c|c|}
\hline & Effective taxes & As a percentage of total taxation \\
\hline Belgium & 21.5 & 24.4 \\
\hline Czech Rep. & 20.6 & 30.5 \\
\hline Denmark & 32.7 & 32.1 \\
\hline Germany & 19.4 & 27.4 \\
\hline Estonia & 22.8 & 40.0 \\
\hline Ireland & 23.8 & 36.6 \\
\hline Greece & 15.8 & 36.5 \\
\hline Spain & 15.1 & 26.6 \\
\hline France & 19.8 & 25.5 \\
\hline Italy & 17.5 & 25.2 \\
\hline Cyprus & 18.8 & 39.5 \\
\hline Latvia & 18.0 & 38.7 \\
\hline Lithuania & 17.3 & 38.2 \\
\hline Hungary & 26.4 & 38.0 \\
\hline Netherlands & 24.7 & 29.8 \\
\hline Austria & 21.7 & 28.1 \\
\hline Poland & 19.8 & 37.6 \\
\hline Portugal & 18.6 & 38.2 \\
\hline Slovenia & 23.6 & 36.0 \\
\hline Slovakia & 18.9 & 35.9 \\
\hline Finland & 26.7 & 31.0 \\
\hline Sweden & 27.3 & 27.3 \\
\hline UK & 18.2 & 31.5 \\
\hline Norway & 29.4 & 27.2 \\
\hline Average & 22.1 & 33.2 \\
\hline & &
\end{tabular}

Source: European Commission / Sample 25 countries

\footnotetext{
${ }^{3}$ We do not allow for the provision of subsidies by the government, since in that case, and given that we have a two-agent model, our tax system would become progressive (as in Atkinson and Stiglitz, 1980). We leave this for future work.
} 
Our main result is that the introduction of consumption taxes into a model with income taxes only generates a tradeoff between efficiency and redistribution. In particular, the economy with both income and consumption taxes is more efficient than the economy with income taxes only, in the sense that output is higher in the former case. Moreover, both groups of households are better off, both in terms of income and welfare, in the economy with income and consumption taxes. On the other hand, income inequality increases once consumption taxes are introduced in the economy, which simply implies that capitalists benefit more than workers as we move to a more efficient economy. Hence, it seems that we are able to confirm the widespread belief mentioned above that a switch to a mix of income and consumption taxes creates welfare gains for both the economy as a whole and the various social classes individually, but at the cost of higher net income inequality. In other words, the introduction of consumption taxes reduces the progressivity of the tax system. From a normative point of view, this may also justify the design of a set of subsidies policies which will aim to outweigh the regressive effects of the otherwise more efficient consumption taxes.

The rest of the paper is organized as follows. Section 2 discusses briefly the relevant literature and explains how the paper differentiates from it. Section 3 describes the economic environment and defines, first the Decentralized, and then, the Ramsey, General Equilibrium (DGE and RGE respectively). Section 4 discusses the parameter values used in numerical solutions, and presents and discusses the numerical results. Section 5 presents the case of a nonutilitarian government. Finally, Section 6 concludes. Various algebraic details are included in an appendix.

\section{Related Literature and How Our Paper is Differentiated}

Our paper belongs to the huge - and still growing - literature on the relationship between fiscal policy, and in particular taxation, and macroeconomic outcomes. A key question in this literature concerns how changes in the tax mix affect, among others, growth, welfare and inequality.

In particular, the literature on optimal Ramsey taxation studies extensively the role of consumption taxes on the grounds of efficiency. It is a common belief that a shift from income taxation to consumption taxes raises aggregate efficiency since it induces capital accumulation and reduces the so-called under-investment problem due to high capital income taxation. Notice that an increase in the income tax rate decreases future consumption relative to current consumption. Thus, the choice between income and consumption taxes can be thought of as the choice of the optimal taxes on current and future consumption. In this vein, Coleman (2000) studies optimal policy in a representative agent model where the government is allowed to choose optimally capital income and labour income taxes, as well as taxes on consumption expenditure, and finds that there are large welfare gains when the government uses a mix of 


\section{ECONOMIDES, RIZOS Optimal Taxation, Efficiency and Redistribution}

income and consumption taxes. Zhang et al. (2007) study optimal Ramsey taxation in a neoclassical growth, representative agent model in order to examine the superiority, in terms of welfare, of consumption taxes relative to income taxes. Particularly, they choose optimally a mix of fiscal instruments that consists of capital income, labour income and consumption taxes as well as subsidies on net investment. Their main findings are that: (a) the government should tax leisure and private consumption at the same rate and should subsidize net investment at the same rate with capital income taxation, (b) the tax rate on capital should be higher than that on labour so as to increase labour and reduce leisure, and (c) all taxes and subsidies should be constant over time, except from the capital income tax rate which can differ in the initial period. In the same context, Motta and Rossi (2013) study optimal fiscal and monetary policy in a new Keynesian representative agent model with public debt and examine how the Ramsey policy changes when the government chooses optimally labour income taxes and consumption taxes. They show that the introduction of consumption taxes generates substantial welfare gains which are not limited to the steady state but also are evident in the dynamic stochastic equilibrium. Moreover, the optimal size of the provided public services is remarkably higher in the presence of consumption taxes.

In addition to the above, the literature on endogenous growth models has investigated extensively the effects of both income and consumption taxes on economic growth. For instance, Barro (1990) incorporates a public sector into a simple representative agent model of endogenous growth, in which, the engine of growth is productive public expenditures. The aim is to show, among others, how the externalities associated with public expenditures and income taxes affect negatively savings and economic growth. Also, King and Rebelo (1990), Rebelo (1991), Pecorino (1993) and Stokey and Rebelo (1995), all within a representative consumer setup, show that income taxes are in general growth reducing. On the other hand, the impact of consumption taxes on growth is ambiguous and depends on model specifications. MilesiFerretti and Roubini (1998), using a representative agent model, examine the macroeconomic effects of taxes on capital income, labour income and consumption spending on economic growth and aggregate welfare. In their model, the engine of growth is the accumulation of human and physical capital. In particular, they show that the effects of the different taxes on economic growth depend crucially on the specification of leisure and the structure as well as the tax treatment of the human capital accumulation sector. Taxes on capital and labour income have a negative effect on growth. Also, consumption taxes hurt long-term growth, when government spending as a fraction of output is constant and, thus, the revenues raised due to the presence of the consumption tax are rebated in a lump sum way to consumers. As a result, the effect on labour supply is negative and economic growth decreases. Following Jones, Manuelli and Rossi (1993), where the optimal tax mix consists in setting all taxes equal to zero in the long run and accumulating government budget surpluses in order to finance future 
government spending through the returns of its assets, Milesi-Ferretti and Roubini (1998) focus on the growth maximizing tax mix in the long run rather than on welfare maximizing tax policy.

For reasons of simplification, they assume that labour is inelastically supplied and, thus, consumption tax has no impact on economic growth and limit their analysis to the study of the optimal structure of taxation between human and physical capital taxation. On the contrary, Rebelo (1991) claims that changes in consumption taxes do not affect growth if government spending is allowed to change parallel to consumption taxes. This happens because the extra tax revenues due to an increase in the consumption tax rate are not rebated to consumers and the income and substitution effects of the consumption tax leave unaffected labour supply and, thus, growth.

Therefore, the main lesson derived from most of the above studies that use representative agent models in order to investigate the implications of the use of income and consumption taxes for the macroeconomy, is that consumption taxes are a less distortive policy instrument relative to income taxes, and, thus, are good on the grounds of efficiency. This conclusion seems to be in accordance with what most people tend to believe and may explain the popularity of consumption taxes relative to income taxes as a tax policy instrument.

However, and leaving aside efficiency issues, it is also believed that the use of consumption taxes increases inequality by hurting the poor people. Hence, it is also crucial to study the implications of the use of consumption taxes for the distribution of income. This extremely interesting and important question, regarding the distributional implications of the consumption tax rates, has paradoxically attracted very limited attention by the researchers. Few notable exceptions include, for instance, Penalosa and Turnovsky (2008), Correia (2010), and Krusell et al. (1996), all of whom however, focus on exogenous tax policy systems and reforms.

In particular, Penalosa and Turnovsky (2008) study the effects of exogenous changes in capital, labour and consumption taxes on the wealth distribution in a model in which agents differ in initial capital endowments and the labour supply is endogenously determined. Their main result is that exogenous tax changes that reduce the labour supply not only decrease output but also decrease after tax income inequality. Moreover, the higher the consumption tax rate the smaller the decrease in output and inequality. On the other hand, Correia (2010) uses a model in which she allows for heterogeneity across agents and shows that the exogenous substitution of income taxes with a flat consumption tax rate increases aggregate efficiency and reduces income inequality. However, this occurs due to the presence of nondiscriminatory lump-sum transfers that increase the progressivity of the tax system. This in turn more than outweighs the regressive consequences of the use of consumption taxes. Finally, Krusell et al. (1996) study the efficiency and distributional effects of an exogenous switch from an income tax to a consumption tax using a neoclassical growth model in which political-equilibrium theory is applied. Heterogeneity across agents is based on their wealth holdings and/or labour 


\section{ECONOMIDES, RIZOS Optimal Taxation, Efficiency and Redistribution}

productivity. They examine whether an economy with consumption taxes only is superior to the same economy with income taxes only, when government's outlays are used for redistribution through transfers. They find that income taxes are generally a better policy instrument than consumption taxes in the sense that the use of more distortionary taxes results in higher welfare, since they reduce the level of government activity. On the other hand, tax systems with both income and consumption taxes are better relative to one-tax systems since the government has at its disposal more policy instruments. Moreover, they find that when the aim of the government is to finance the provision of public goods and not to provide any transfers to agents, then less distortionary taxes are superior. Concerning the distributional implications of the aforementioned tax changes Krussell et al. find that only very rarely the median agent improves her welfare after a change in the tax mix (for example, when the economy switches from a one tax-system to a two-tax system, the median agent gains whereas the rest - those having the same labor efficiency with the median agent but different non-human wealth - lose).

Therefore, our paper differs to the existing relevant literature, discussed briefly above, in that at the same time, first, we introduce consumption taxes in an otherwise standard neoclassical growth model with heterogeneous agents and income taxes only, and second, we focus on optimal Ramsey policies. In other words, by combining all these elements, our paper somehow generalizes the relevant literature, which so far had given emphasis to specific aspects of this problem ignoring at the same time other important dimensions. This more generalized setup not only allows us to investigate the properties of optimal taxation once consumption taxes are introduced, but also explore its aggregate and distributional implications of this richer menu of tax policies. Namely, we show that in such a setup, the introduction of optimally chosen consumption taxes in an economy with income taxes only, implies substantial aggregate output and welfare gains, thus making all agents better off relative to the case in which public spending is financed by income taxes only. However, in the absence of ex-post redistributive schemes, net income inequality increases in the sense that capitalists benefit more relative to workers by the introduction of consumption taxes. Moreover, and since our results are numerical, we should mention that they do not depend on whether the government is utilitarian or not, and are relatively robust to various parameter changes.

In summary, this is a paper that focuses on both efficiency and distributional issues in the sense that it studies the implications of the use of less distorting policy instruments, i.e. consumption taxes, for both the economy as a whole and the distribution of income among capital owners and workers. Obviously, from this perspective, it should be considered as a positive exercise which does not provide normative suggestions on how policy should deal with the unequal distribution of income. 


\section{The Economy}

\subsection{Description of the Model}

The setup is a two-period deterministic version of the standard neoclassical growth model comprised of households, firms and a government. This model is extended to allow for heterogeneity among agents. In particular, the private sector consists of two groups of households that are assumed to differ in capital holdings and labor productivity. Following Judd (1985) and Lansing (1999), capital is in the hands of a small group of agents, called capitalists, while workers, who, by assumption, form the majority in our economy, are not allowed to make savings ${ }^{4}$. Also, as in Hornstein et al. (2005), the aggregate labor input is a linear function of high-skilled and low-skilled labor, for capitalists and workers respectively, with different factor productivities. Households derive utility from private consumption, leisure and the provision of public goods. For simplicity, we use a logarithmic utility function in which preferences are separable in all three components. In the first period, capitalists consume, work and save, while workers only consume and work. In the second period both groups of households consume and work. In the production sector of the economy, private firms, which are owned to capitalists, maximize their profits by using capital and labour inputs to produce a single homogeneous good. They produce this good using constant returns to scale production function, which is strictly concave, differentiable and strictly increasing in both inputs. There are competitive factor markets. Each capitalist owns a firm and, thus, profits, if any, are distributed to capitalists. Also, there is private good production in both periods.

The government needs revenues to provide public goods in both periods ${ }^{5}$. To finance these utility - enhancing public goods, it imposes linear taxes on income and consumption spending. For simplicity, we abstract from public debt so the government budget is balanced in each period. Policy is chosen optimally. We will examine optimal policy with commitment, the socalled Ramsey policy, in which policy is chosen once-and-for-all at the beginning of the time horizon. Thus, the government will maximize a weighted average of capitalists' and workers'

\footnotetext{
${ }^{4}$ The assumption that workers are not allowed to save is not crucial for the results regarding the efficiency gains or losses of the later-discussed tax changes. As far as it concerns the distributional implications of the same tax changes, we report that they continue to hold even if workers are allowed to save provided that they face a higher - than capitalists - transaction cost for participating at the capital market. Results are available upon request.

${ }^{5}$ The simplifying assumption that there is public good provision only in second period is very common in the relevant literature (see e.g. Fischer (1980), Persson and Tabellini (1994),(2000) and many others). Here, we assume that there are both public good provision and private good production in both periods (as in Martin (2010)).
} 
welfare by choosing income taxes, consumption taxes, as well as the associated amount of the public good.

Total population size, $N$, is exogenous and constant. Workers are indexed by the subscript $w=1,2, \ldots, N^{w}$ and capitalists by the subscript $k=1,2, \ldots N^{k}$. In particular, among $N, N^{k}<$ $N$ are identical capitalists, while the majority $N^{w}=N-N^{k}$ and $N^{w}>N^{k}$ are identical workers. There are also $f=1,2, \ldots, N^{f}$ private firms where the number of firms, for simplicty, equals the number of capitalists, $N^{k}=N^{f}$. Notice also, that there is no social mobility between the two groups.

\subsection{Households as capitalists}

Each capitalist $k$ chooses consumption, $c_{k, 1}$ and $c_{k, 2}$, labour effort, $l_{k, 1}$ and $l_{k, 2}$, in both periods and savings in the first period, $k_{k, 2}$ in order to maximize her two-period lifetime welfare:

$$
\begin{gathered}
U_{k}=\mu_{1} \log c_{k, 1}+\mu_{2} \log \left(1-l_{k, 1}\right)+\mu_{3} \log g_{1}+\beta\left[\mu_{1} \log c_{k, 2}\right. \\
\left.+\mu_{2} \log \left(1-l_{k, 2}\right)+\mu_{3} \log g_{2}\right]
\end{gathered}
$$

subject to her two consecutive budget constraints:

$$
\begin{aligned}
& \left(1+\tau_{1}^{c}\right) c_{k, 1}+k_{k, 2}=(1-\delta) k_{k, 1}+\left(1-\tau_{1}^{y}\right)\left(r_{1} k_{k, 1}+w_{1}^{k} l_{k, 1}\right) \\
& \left(1+\tau_{2}^{c}\right) c_{k, 2}+k_{k, 3}=(1-\delta) k_{k, 2}+\left(1-\tau_{2}^{y}\right)\left(r_{2} k_{k, 2}+w_{2}^{k} l_{k, 2}\right)
\end{aligned}
$$

where the parameters $\mu_{1}, \mu_{2}, \mu_{3}>0$ are preference weights, $r_{1}, r_{2}, w_{1}^{k}, w_{2}^{k}$ are the gross returns to capital and labour respectively in both periods, $0<\beta<1$ is the discount rate, $0 \leq \delta \leq 1$ is the capital depreciation rate and $0 \leq \tau_{1}^{y}, \tau_{2}^{y}, \tau_{1}^{c}, \tau_{2}^{c}<1$ are tax rates on income and consumption spending in both periods. Notice that capitalists are not allowed to leave bequests and, thus, we set $k_{k, 3} \equiv$ 0 . Since the assumptions we make, regarding the operation of firms (see below), imply zero profits in equilibrium, we omit them from the capitalist's budget constraints.

The first order conditions include the two consecutive budget constraints and the optimality conditions with respect to $l_{k, 1}, l_{k, 2}$ and $k_{k, 2}$ :

$$
\begin{gathered}
\frac{\mu_{2}}{\left(1-l_{k, 1}\right)}=\frac{\mu_{1}\left(1-\tau_{1}^{y}\right) w_{1}^{k}}{\left(1+\tau_{1}^{c}\right) c_{k, 1}} \\
\frac{\mu_{2}}{\left(1-l_{k, 2}\right)}=\frac{\mu_{1}\left(1-\tau_{2}^{y}\right) w_{2}^{k}}{\left(1+\tau_{2}^{c}\right) c_{k, 2}} \\
\frac{1}{\left(1+\tau_{1}^{c}\right) c_{k, 1}}=\frac{\beta\left[1-\delta+\left(1-\tau_{2}^{y}\right) r_{2}\right]}{\left(1+\tau_{2}^{c}\right) c_{k, 2}}
\end{gathered}
$$


Note that $k_{k, 1}$ is the beginning-of-the-first period capital stock and is predetermined. The first two static equations, 1.3 and 1.4, respectively, give the labour-supply decisions for the capitalist in each period, whereas the last one, equation 1.5, is the standard Euler equation.

\subsection{Households as Workers}

Each worker w chooses consumption and labour effort in both periods, $c_{w, 1}, c_{w, 2}$ and $l_{w, 1}, l_{w, 2}$ respectively, in order to maximize her two-period lifetime welfare:

$$
\begin{gathered}
U_{w}=\mu_{1} \log c_{w, 1}+\mu_{2} \log \left(1-l_{w, 1}\right)+\mu_{3} \log g_{1}+\beta\left[\mu_{1} \log c_{w, 2}\right. \\
\left.+\mu_{2} \log \left(1-l_{w, 2}\right)+\mu_{3} \log g_{2}\right]
\end{gathered}
$$

subject to her two consecutive budget constraints:

$$
\begin{aligned}
& \left(1+\tau_{1}^{c}\right) c_{w, 1}=\left(1-\tau_{1}^{y}\right) w_{1}^{w} l_{w, 1} \\
& \left(1+\tau_{2}^{c}\right) c_{w, 2}=\left(1-\tau_{2}^{y}\right) w_{2}^{w} l_{w, 2}
\end{aligned}
$$

The first order conditions include the two consecutive budget constraints and the optimality conditions with respect to $l_{w, 1}$ and $l_{w, 2}$ :

$$
\begin{aligned}
& \frac{\mu_{2}}{\left(1-l_{w, 1}\right)}=\frac{\mu_{1}\left(1-\tau_{1}^{y}\right) w_{1}^{w}}{\left(1+\tau_{1}^{c}\right) c_{w, 1}} \\
& \frac{\mu_{2}}{\left(1-l_{w, 2}\right)}=\frac{\mu_{1}\left(1-\tau_{2}^{y}\right) w_{2}^{w}}{\left(1+\tau_{2}^{c}\right) c_{w, 2}}
\end{aligned}
$$

Note that the workers are not allowed to save. The above two static equations, 1.8 and 1.9 respectively, give the labour-supply decisions for the worker.

\subsection{Firms}

There is production in both periods. There are $f=1,2, \ldots, N^{f}$ firms owned by capitalists. Thus, each capitalist owns a firm and hence $N^{k}=N^{f}$. Each firm maximizes its profits in each period:

$$
\begin{gathered}
\Pi_{1}=y_{f, 1}-r_{1} k_{f, 1}-w_{1}^{k} l_{f, 1}^{k}-w_{1}^{w} l_{f, 1}^{w} \\
\Pi_{2}=y_{f, 2}-r_{2} k_{f, 2}-w_{2}^{k} l_{f, 2}^{k}-w_{2}^{w} l_{f, 2}^{w}
\end{gathered}
$$

where output in period 1 and 2 is produced according to the following standard Cobb-Douglas production functions: 
ECONOMIDES, RIZOS Optimal Taxation, Efficiency and Redistribution

$$
\begin{aligned}
& y_{f, 1}=A k_{f, 1}{ }^{a} L_{f, 1}{ }^{1-a} \\
& y_{f, 2}=A k_{f, 2}{ }^{a} L_{f, 2}{ }^{1-a}
\end{aligned}
$$

where $k_{f, 1}, k_{f, 2}$ are the capital inputs supplied by capitalists, $L_{f, 1}$ and $L_{f, 2}$ are the aggregate effective labour inputs, while $A>0$ and $0<\alpha<1$ are usual technology parameters.

We assume that capitalists are more skilled than workers, and, therefore, the two types of agents face different factor productivities. Thus, as in Hornstein et al. (2005), we generalize the production function by disaggregating the contributions to production of the two labour inputs. We assume that the aggregate effective labour input $L_{f, t}$ is a weighted linear function of labour supplied by high-skilled agents (i.e. capitalists) and labour supplied by low-skilled agents (i.e. workers), $l_{f, t}^{k}$ and $l_{f, t}^{w}$ respectively, where the weights, $A^{k}$ and $A^{w}$, reflect the different productivities/skills between capitalists and workers, and where it holds that $A^{k}>A^{w}$ :

$$
L_{f, t}=A^{k} l_{f, t}^{k}+A^{w} l_{f, t}^{w}
$$

Thus, the production functions presented in equations 1.12 and 1.13 can be written as:

$$
\begin{aligned}
& y_{f, 1}=A k_{f, 1}{ }^{a}\left(A^{k} l_{f, 1}^{k}+A^{w} l_{f, 1}^{w}\right)^{1-a} \\
& y_{f, 2}=A k_{f, 2}{ }^{a}\left(A^{k} l_{f, 2}^{k}+A^{w} l_{f, 2}^{w}\right)^{1-a}
\end{aligned}
$$

where $k_{f, 1}, k_{f, 2}$ are the capital inputs, $l_{f, 1}^{k}, l_{f, 2}^{k}$ are the labour inputs supplied by capitalists and $l_{f, 1}^{w}, l_{f, 2}^{w}$ are the labour inputs supplied by workers.

The first order conditions of the above profit maximization problems with respect to $k_{f, 1}$, $l_{f, 1}^{k}, l_{f, 1}^{w}, k_{f, 2}, l_{f, 2}^{k}$ and $l_{f, 2}^{w}$ are respectively:

$$
\begin{gathered}
r_{1}=a A k_{f, 1}^{a-1}\left(A^{k} l_{f, 1}^{k}+A^{w} l_{f, 1}^{w}\right)^{1-a} \\
w_{1}^{k}=(1-a) A^{k} A{k_{f, 1}}^{a}\left(A^{k} l_{f, 1}^{k}+A^{w} l_{f, 1}^{w}\right)^{-a} \\
w_{1}^{w}=(1-a) A^{w} A{k_{f, 1}}^{a}\left(A^{k} l_{f, 1}^{k}+A^{w} l_{f, 1}^{w}\right)^{-a} \\
r_{2}=a A k_{f, 2}^{a-1}\left(A^{k} l_{f, 2}^{k}+A^{w} l_{f, 2}^{w}\right)^{1-a} \\
w_{2}^{k}=(1-a) A^{k} A k_{f, 2}^{a}\left(A^{k} l_{f, 2}^{k}+A^{w} l_{f, 2}^{w}\right)^{-a} \\
w_{2}^{w}=(1-a) A^{w} A k_{f, 2}{ }^{a}\left(A^{k} l_{f, 2}^{k}+A^{w} l_{f, 2}^{w}\right)^{-a}
\end{gathered}
$$

where, since $A^{k}>A^{w}, w_{1}^{k}>w_{1}^{w}$ and $w_{2}^{k}>w_{2}^{w}$. 


\subsection{Government}

The government operates in each period. It needs revenues to provide utility-enhancing public goods and, therefore, we assume that it finances the provision of these public goods by a mix of linear income and consumption taxes, which are both proportional to their own tax base.

The two consecutive government budget constraints, written in aggregate terms, are:

$$
\begin{aligned}
& G_{1}=N^{k}\left[\tau_{1}^{y}\left(r_{1} k_{k, 1}+w_{1}^{k} l_{k, 1}\right)+\tau_{1}^{c} c_{k, 1}\right]+N^{w}\left[\tau_{1}^{y} w_{1}^{w} l_{w, 1}+\tau_{1}^{c} c_{w, 1}\right] \\
& G_{2}=N^{k}\left[\tau_{2}^{y}\left(r_{2} k_{k, 2}+w_{2}^{k} l_{k, 2}\right)+\tau_{2}^{c} c_{k, 2}\right]+N^{w}\left[\tau_{2}^{y} w_{2}^{w} l_{w, 2}+\tau_{2}^{c} c_{w, 2}\right]
\end{aligned}
$$

where $G_{t} \equiv N g_{t}$ is the total provision of the public good in each period t.

\subsection{Market clearing Conditions}

Each capitalist owns a firm. Hence, it holds that $N^{k}=N^{f}=N-N^{w}$. It is convenient to define the population shares of the two groups as $n^{k}=\frac{N^{k}}{N}$ and $n^{w}=\frac{N^{w}}{N}=1-n^{k}$. The market clearing conditions for the capital market are:

$$
\begin{aligned}
& N^{f} k_{f, 1}=N^{k} k_{k, 1} \Leftrightarrow k_{f, 1}=k_{k, 1} \\
& N^{f} k_{f, 2}=N^{k} k_{k, 2} \Leftrightarrow k_{f, 2}=k_{k, 2}
\end{aligned}
$$

The labour market clearing conditions imply that labour demand equals labour supply. Hence the labour market clearing conditions are:

$$
\begin{gathered}
N^{f} l_{f, 1}^{k}=N^{k} l_{k, 1} \Leftrightarrow l_{f, 1}^{k}=l_{k, 1} \\
N^{f} l_{f, 2}^{k}=N^{k} l_{k, 2} \Leftrightarrow l_{f, 2}^{k}=l_{k, 2} \\
N^{f} l_{f, 1}^{w}=N^{w} l_{w, 1} \Leftrightarrow n^{k} l_{f, 1}^{w}=n^{w} l_{w, 1} \Leftrightarrow l_{f, 1}^{w}=\frac{n^{w}}{n^{k}} l_{w, 1} \\
N^{f} l_{f, 2}^{w}=N^{w} l_{w, 2} \Leftrightarrow n^{k} l_{f, 2}^{w}=n^{w} l_{w, 2} \Leftrightarrow l_{f, 2}^{w}=\frac{n^{w}}{n^{k}} l_{w, 2}
\end{gathered}
$$

\subsection{Decentralized Competitive Equilibrium (for given policy)}

Now we can define the Decentralized Competitive Equilibrium (DCE) for any feasible policy. 
Definition 1: (Decentralized Competitive Equilibrium). Given the paths of the independent policy instruments $\left\{\tau_{t}^{y}, \tau_{t}^{c}, g_{t}\right\}_{t=1,2}$ a decentralized equilibrium is defined to be a sequence of allocations $\left\{c_{k, t}, l_{k, t}, k_{k, t+1}\right\}_{t=1,2}$ for the capitalist and $\left\{c_{w, t}, l_{w, t}\right\}_{t=1,2}$ for the worker and prices $\left\{r_{t}, w_{t}^{k}, w_{t}^{w}\right\}_{t=1,2}$, such that households maximize utility and firms maximize profits given prices and economic policy, all markets clear and all constraints are satisfied.

In the DCE, both types of households (capitalists and workers) maximize lifetime utility, firms maximize profits, all constraints (including the government's budget constraint) are satisfied and all markets clear. This DCE is summarized by the following equations. Notice that all quantities are in per capita terms:

$$
\begin{aligned}
& \left(1+\tau_{1}^{c}\right) c_{k, 1}+k_{k, 2}=(1-\delta) k_{k, 1}+\left(1-\tau_{1}^{y}\right)\left(r_{1} k_{k, 1}+w_{1}^{k} l_{k, 1}\right) \\
& \left(1+\tau_{2}^{c}\right) c_{k, 2}=(1-\delta) k_{k, 2}+\left(1-\tau_{2}^{y}\right)\left(r_{2} k_{k, 2}+w_{2}^{k} l_{k, 2}\right) \\
& \frac{\mu_{2}}{\left(1-l_{k, 1}\right)}=\frac{\mu_{1}\left(1-\tau_{1}^{y}\right) w_{1}^{k}}{\left(1+\tau_{1}^{c}\right) c_{k, 1}} \\
& \frac{\mu_{2}}{\left(1-l_{k, 2}\right)}=\frac{\mu_{1}\left(1-\tau_{2}^{y}\right) w_{2}^{k}}{\left(1+\tau_{2}^{c}\right) c_{k, 2}} \\
& \frac{1}{\left(1+\tau_{1}^{c}\right) c_{k, 1}}=\frac{\beta\left[1-\delta+\left(1-\tau_{2}^{y}\right) r_{2}\right]}{\left(1+\tau_{2}^{c}\right) c_{k, 2}} \\
& \left(1+\tau_{1}^{c}\right) c_{w, 1}=\left(1-\tau_{1}^{y}\right) w_{1}^{w} l_{w, 1} \\
& \left(1+\tau_{2}^{c}\right) c_{w, 2}=\left(1-\tau_{2}^{y}\right) w_{2}^{w} l_{w, 2} \\
& \frac{\mu_{2}}{\left(1-l_{w, 1}\right)}=\frac{\mu_{1}\left(1-\tau_{1}^{y}\right) w_{1}^{w}}{\left(1+\tau_{1}^{c}\right) c_{w, 1}} \\
& \frac{\mu_{2}}{\left(1-l_{w, 2}\right)}=\frac{\mu_{1}\left(1-\tau_{2}^{y}\right) w_{2}^{w}}{\left(1+\tau_{2}^{c}\right) c_{w, 2}} \\
& g_{1}=n^{k} \tau_{1}^{y}\left(r_{1} k_{k, 1}+w_{1}^{k} l_{k, 1}\right)+n^{w} \tau_{1}^{y} w_{1}^{w} l_{w, 1}+\tau_{1}^{c}\left(n^{k} c_{k, 1}+n^{w} c_{w, 1}\right) \\
& g_{2}=n^{k} \tau_{2}^{y}\left(r_{2} k_{k, 2}+w_{2}^{k} l_{k, 2}\right)+n^{w} \tau_{2}^{y} w_{2}^{w} l_{w, 2}+\tau_{2}^{c}\left(n^{k} c_{k, 2}+n^{w} c_{w, 2}\right)
\end{aligned}
$$


where in the above equations we use:

$$
\begin{gathered}
n^{k} y_{f, 1}=A\left(n^{k} k_{k, 1}\right)^{a}\left(n^{k} A^{k} l_{k, 1}+n^{w} A^{w} l_{w, 1}\right)^{1-a} \\
n^{k} y_{f, 2}=A\left(n^{k} k_{k, 2}\right)^{a}\left(n^{k} A^{k} l_{k, 2}+n^{w} A^{w} l_{w, 2}\right)^{1-a} \\
r_{1}=a A{k_{k, 1}}^{a-1}\left(A^{k} l_{k, 1}+\frac{n^{w}}{n^{k}} A^{w} l_{w, 1}\right)^{1-a} \\
w_{1}^{k}=(1-a) A^{k} A{k_{k, 1}}^{a}\left(A^{k} l_{k, 1}+\frac{n^{w}}{n^{k}} A^{w} l_{w, 1}\right)^{-a} \\
w_{1}^{w}=(1-a) A^{w} A{k_{k, 1}}^{a}\left(A^{k} l_{k, 1}+\frac{n^{w}}{n^{k}} A^{w} l_{w, 1}\right)^{-a} \\
r_{2}=a A k_{k, 2}^{a-1}\left(A^{k} l_{k, 2}+\frac{n^{w}}{n^{k}} A^{w} l_{w, 2}\right)^{1-a} \\
w_{2}^{k}=(1-a) A^{k} A k_{k, 2}{ }^{a}\left(A^{k} l_{k, 2}+\frac{n^{w}}{n^{k}} A^{w} l_{w, 2}\right)^{-a} \\
w_{2}^{w}=(1-a) A^{w} A k_{k, 2}^{a}\left(A^{k} l_{k, 2}+\frac{n^{w}}{n^{k}} A^{w} l_{w, 2}\right)^{-a}
\end{gathered}
$$

Instead of the equations 2.1-2.2 (capitalist's budget constraints), we can use the two resource constraints of the economy which are given below:

$$
\begin{gathered}
n^{k} c_{k, 1}+n^{w} c_{w, 1}+n^{k} k_{k, 2}-(1-\delta) n^{k} k_{k, 1}+g_{1}=n^{k} y_{f, 1} \\
n^{k} c_{k, 2}+n^{w} c_{w, 2}-(1-\delta) n^{k} k_{k, 2}+g_{2}=n^{k} y_{f, 2}
\end{gathered}
$$

Hence, we end up with a system of 11 equations (2.1-2.11 or 2.3-2.13) in 9 endogenous variables: $\left\{c_{k, 1}, c_{k, 2}, k_{k, 2}, l_{k, 1}, l_{k, 2}, c_{w, 1}, c_{w, 2}, l_{w, 1}, l_{w, 2}\right\}$ and 2 of the policy instruments $\left\{g_{1}, g_{2}\right\}$ which adjust to satisfy the two consecutive government's budget constraints. This is for any tax policy $\left\{\tau_{1}^{y}, \tau_{2}^{y}, \tau_{1}^{c} \tau_{2}^{c}\right\}$. In the case of Ramsey policy the above equations will serve as the constraints to the Ramsey government when the latter chooses the policy instruments in the beginning of the time horizon subject to the above equations. Irrespectively of how policy is chosen below we need to make sure that the DCE system delivers a meaningful numerical solution. We check this in subsection 5.1. 
ECONOMIDES, RIZOS Optimal Taxation, Efficiency and Redistribution

\subsection{Ramsey General Equilibrium}

We will consider optimal policy with commitment. In this case, the so-called Ramsey General Equilibrium, policy is chosen once-and-for-all at the beginning of the time horizon before private agents make their choices. Notice that the government is benevolent and, thus, maximizes a weighted average of the utilities of the two groups of households, taking into account the DCE equations. The problem is solved by backward induction. This means that we first solve the private agents' problem and then we solve for optimal policy.

We now define the Ramsey equilibrium, i.e. when the policy-maker is able to commit to future policies.

Definition 2: (Ramsey General Equilibrium). A Ramsey General Equilibrium is a sequence of government policies $\left\{\tau_{t}^{y}, \tau_{t}^{c}, g_{t}\right\}_{t=1,2}$, allocations $\left\{c_{k, t}, l_{k, t}, k_{k, t+1}\right\}_{t=1,2}$ for the capitalist and allocations $\left\{c_{w, t}, l_{w, t}\right\}_{t=1,2}$ for the worker which solve the following maximization problem:

$$
\max _{\left\{\tau_{t}^{y}, \tau_{t}^{c}, g_{t}\right\}_{t=1,2}}\left[(1-\gamma) U_{k}+\gamma U_{w}\right]
$$

subject to the DCE equations and taking as given the beginning of the first period capital stock, $k_{k, 1}$.

Notice that, in order to make the Ramsey policy problem non-trivial, we impose a restriction on the first-period income tax rate $\tau_{1}^{y}$, for example by taking it as given at a small number (for instance, 0.15 at our numerical solution - see also below). This approach rules out taxing heavily the initial capital stock which would be equivalent to a non-distorting lump-sum tax, since $k_{k, 1}$ is in fixed supply.

We assume commitment technologies, i.e. the government can commit itself to the policies that will be in place arbitrarily into the second period. The sequence of time is as follows. Policy is chosen once-and-for-all in the beginning of period 1 before any private decisions are made. We solve the problem by backward induction. This means that the agents first solve their optimization problems for given policy and then the government chooses the policy instruments $\tau_{2}^{y}, \tau_{1}^{c} \tau_{2}^{c}, g_{1}, g_{2}$ to maximize a weighted average of the utility of the two agents, $(1-\gamma) U_{k}+\gamma U_{w}$ subject to the DCE equations derived earlier, where the given political preferences $0 \leq \gamma \leq 1$ and $0 \leq 1-\gamma \leq 1$ measure respectively the influence of the two social classes, workers and capitalists, in the policy setting process. 
The Lagrangian equation of the Ramsey government's optimization problem is:

$$
\begin{aligned}
& L=(1-\gamma)\left\{\mu_{1} \log c_{k, 1}+\mu_{2} \log \left(1-l_{k, 1}\right)+\beta\left[\mu_{1} \log c_{k, 2}+\mu_{2} \log \left(1-l_{k, 2}\right)\right]\right\} \\
& +\gamma\left\{\mu_{1} \log c_{w, 1}\right. \\
& \left.+\mu_{2} \log \left(1-l_{w, 1}\right)+\beta\left[\mu_{1} \log c_{w, 2}+\mu_{2} \log \left(1-l_{w, 2}\right)\right]\right\} \\
& +\mu_{3} \log \left\{n^{k} \tau_{1}^{y}\left(r_{1} k_{k, 1}+w_{1}^{k} l_{k, 1}\right)+n^{w} \tau_{1}^{y} w_{1}^{w} l_{w, 1}\right. \\
& \left.+\tau_{1}^{c}\left(n^{k} c_{k, 1}+n^{w} c_{w, 1}\right)\right\} \\
& +\beta \mu_{3} \log \left\{n^{k} \tau_{2}^{y}\left(r_{2} k_{k, 2}+w_{2}^{k} l_{k, 2}\right)+n^{w} \tau_{2}^{y} w_{2}^{w} l_{w, 2}\right. \\
& \left.+\tau_{2}^{c}\left(n^{k} c_{k, 2}+n^{w} c_{w, 2}\right)\right\} \\
& +\lambda_{1}\left\{(1-\delta) k_{k, 1}+\left(1-\tau_{1}^{y}\right)\left(r_{1} k_{k, 1}+w_{1}^{k} l_{k, 1}\right)-\left(1+\tau_{1}^{c}\right) c_{k, 1}+k_{k, 2}\right\} \\
& +\beta \lambda_{2}\left\{(1-\delta) k_{k, 2}+\left(1-\tau_{2}^{y}\right)\left(r_{2} k_{k, 2}+w_{2}^{k} l_{k, 2}\right)-\left(1+\tau_{2}^{c}\right) c_{k, 2}\right\} \\
& +\lambda_{3}\left\{\mu_{1}\left(1-\tau_{1}^{y}\right) w_{1}^{k}\left(1-l_{k, 1}\right)-\mu_{2}\left(1+\tau_{1}^{c}\right) c_{k, 1}\right\} \\
& +\beta \lambda_{4}\left\{\mu_{1}\left(1-\tau_{2}^{y}\right) w_{2}^{k}\left(1-l_{k, 2}\right)-\mu_{2}\left(1+\tau_{2}^{c}\right) c_{k, 2}\right\} \\
& +\lambda_{5}\left\{\beta\left(1+\tau_{1}^{c}\right) c_{k, 1}\left[1-\delta+\left(1-\tau_{2}^{y}\right) r_{2}\right]-\left(1+\tau_{2}^{c}\right) c_{k, 2}\right\} \\
& +\lambda_{6}\left\{\left(1-\tau_{1}^{y}\right) w_{1}^{w} l_{w, 1}-\left(1+\tau_{1}^{c}\right) c_{w, 1}\right\} \\
& +\beta \lambda_{7}\left\{\left(1-\tau_{2}^{y}\right) w_{2}^{w} l_{w, 2}-\left(1+\tau_{2}^{c}\right) c_{w, 2}\right\} \\
& +\lambda_{8}\left\{a A k_{k, 1}^{a-1}\left(A^{k} l_{k, 1}+\frac{n^{w}}{n^{k}} A^{w} l_{w, 1}\right)^{1-a}-r_{1}\right\} \\
& +\beta \lambda_{9}\left\{a A k_{k, 2}^{a-1}\left(A^{k} l_{k, 2}+\frac{n^{w}}{n^{k}} A^{w} l_{w, 2}\right)^{1-a}-r_{2}\right\} \\
& +\lambda_{10}\left\{(1-a) A^{k} A k_{k, 1} a\left(A^{k} l_{k, 1}+\frac{n^{w}}{n^{k}} A^{w} l_{w, 1}\right)^{-a}-w_{1}^{k}\right\} \\
& +\beta \lambda_{11}\left\{(1-a) A^{k} A k_{k, 2} a\left(A^{k} l_{k, 2}+\frac{n^{w}}{n^{k}} A^{w} l_{w, 2}\right)^{-a}-w_{2}^{k}\right\} \\
& +\lambda_{12}\left\{(1-a) A^{w} A k_{k, 1} a\left(A^{k} l_{k, 1}+\frac{n^{w}}{n^{k}} A^{w} l_{w, 1}\right)^{-a}-w_{1}^{w}\right\} \\
& +\beta \lambda_{13}\left\{(1-a) A^{w} A k_{k, 2} a\left(A^{k} l_{k, 2}+\frac{n^{w}}{n^{k}} A^{w} l_{w, 2}\right)^{-a}-w_{2}^{w}\right\}
\end{aligned}
$$


That is, we follow the dual approach ${ }^{6}$ to the Ramsey policy problem, where the government rechooses the allocations and the policy variables subject to the DCE. The first-order conditions of the above maximization problem are presented in detail at the appendix. Since it is impossible to get an analytical solution of the Ramsey General Equilibrium, we resort to numerical simulations which are presented in the next section.

\section{Numerical Results}

\subsection{Parameterization}

Since the above described general equilibrium cannot be solved analytically, we present numerical solutions using common parameter values. Table 2 below reports the baseline parameter values for technology and preference, as well as the values of the exogenous policy instruments.

Let us discuss, briefly, the parameter values summarized in Table 2. Regarding those parameters related to technology and preference, we use conventional values used by thebusiness cycle literature (see e.g. Angelopoulos et al., 2011, for a DSGE model with tax reforms calibrated to the UK economy). Notice here that when we do not have a priori

Table 2: Benchmark parameter values

\begin{tabular}{c|c|l}
\hline Parameter & Value & \multicolumn{1}{c}{ Definition } \\
\hline \hline$a$ & 0.3 & Share of private capital income to total output \\
$\mu_{1}$ & 0.3 & Weight given to private consumption \\
$\mu_{2}$ & 0.5 & Weight given to leisure \\
$\mu_{3}$ & 0.2 & Weight given to public consumption \\
$A$ & 1 & Total factor productivity (TFP) \\
$A^{\kappa}$ & 5 & TFP for capitalist's productivity \\
$A^{w}$ & 1 & TFP's for worker's productivity \\
$\delta$ & 0.12 & Depreciation rate of private capital \\
$\beta$ & 0.9 & Discount rate \\
$n^{k}$ & 0.3 & Capitalists' population share \\
$n^{w}$ & 0.7 & Workers' population share \\
$\gamma$ & 0.7 & Weight given to workers' welfare \\
$k_{k, 1}$ & 0.05 & Initial capital stock \\
$\tau_{1}^{y}$ & 0.15 & 1st period income tax rate \\
\hline \hline
\end{tabular}

\footnotetext{
${ }^{6}$ We use the dual approach; in contrast to the primal where all prices and taxes are eliminated so that the government is thought of as directly choosing a feasible allocation (see also Economides et al. (2008)).
} 
information about a parameter value, or when different authors use different values, we experiment with a range of values.

Specifically, in the private production function, in equations (1.12) and (1.13), the CobbDouglas exponent on employment, $1-\alpha$, is equal to the labour share of income, 0.7 , which is close to the value used by Angelopoulos et al. (2011); the rest, a, is the exponent on capital. The scale parameter in the production function, $A$, is set at 1 . Also, we set $A^{k}=5$ and $A^{w}=1$, since capitalists are assumed to be more skilled than workers and, therefore, face higher productivity for their labour supply, resulting, in turn, in higher wages. This assumption not only allows us to get a solution regarding labour supply of capitalists within accepted range but also is in line with a strand of literature that has examined the occupational choice of economic agents, usually focusing on the distinction between entrepreneurs and workers and its implications for skill acquisition (see, e.g., Quadrini 2000; Matsuyama 2006; Kambourov and Manovskii 2009) ${ }^{7}$. The time preference rate, $\beta$, is set at 0.9 . For the weights given by the households to private consumption, leisure and public consumption respectively, we assume that $\mu_{1}=0.3, \mu_{2}=0.5$ and $\mu_{3}=0.2$. The latter value is close to the one used by similar studies, whereas the weights assigned to private consumption and leisure imply hours of work within usual ranges. Finally, the capital depreciation rate, $\delta$, is set at 0.12 .

Regarding the capitalists' and workers' population shares in total population we set them to be 0.3 and 0.7 respectively. Notice that $\gamma$ is the weight given by the government to worker's welfare. Thus, when we assume that the government is utilitarian, the policy is chosen by a government that attaches weights $\gamma$ and $(1-\gamma)$ to the utility of workers and capitalists equal to their population shares (see e.g. Angelopoulos et al., 2011). Therefore, we set $\gamma=n^{w}$ and $(1-\gamma)=n^{k} .{ }^{8}$ Furthermore, the first-period capital stock $k_{k, 1}$ is exogenously given and set at 0.05 ; we report that our results are robust to changes in the value of the initial capital stock. Finally, as already said in the previous section, in order to make the Ramsey policy problem non-trivial, we impose a restriction on the first-period income tax rate $\tau_{1}^{y}$, by taking it as given at a small number. Otherwise, the government would choose to tax heavily the initial capital stock which would be equivalent to a non-distorting lump-sum tax, since $k_{k, 1}$ is in fixed supply. Therefore, in our specific numerical simulations we have set the value of $\tau_{1}^{y}$ at 0.15 ; regarding this parameter value see also the discussion in footnote 13 .

\footnotetext{
${ }^{7}$ Notice that our results are robust to changes in these parameter values.

${ }^{8}$ According to Grossman and Helpman (1996), capitalists seem to have more power in the government decision process. Also, as Angelopoulos et al. (2011) claim policies are chosen by governments that may have specific ideological preferences over groups or are preferred by the majority of the voters. Thus, in reality, the governments are not utilitarian. Therefore, it is useful to examine the effects of the introduction of consumption taxes on redistributive incentives in an economic environment where the government cares more or less for one specific group. We check this case in section 6 .
} 
ECONOMIDES, RIZOS Optimal Taxation, Efficiency and Redistribution

\subsection{Revenue-Neutral Tax Reforms When Policy is Exogenous}

Before we study optimal policy, it is useful to study some exogenous policy reforms. In particular, we examine a revenue-neutral change in the second-period income tax rate $\tau_{2}^{y}$ and the impact of this reform on efficiency and redistribution incentives. Initially, we assume that $\tau_{1}^{y}=0.15, \tau_{2}^{y}=0.3$ and $\tau_{1}^{c}=\tau_{2}^{c}=0.2$ whereas $g_{1}, g_{2}$ are residually determined by the two consecutive government's budget constraints. 9 Next, we change the second-period income tax rate $\tau_{2}^{y}$ and, at the same time, we keep the total tax revenues constant. As a result, the consumption taxes are determined residually by the Tax Revenue equation (in each period), which is given by:

$$
T R_{t}=n^{k} \tau_{t}^{y}\left(r_{t} k_{k, t}+w_{t}^{k} l_{k, t}+\Pi_{t}\right)+n^{w} \tau_{t}^{y} w_{t}^{w} l_{w, t}+\tau_{t}^{c}\left(n^{k} c_{k, t}+n^{w} c_{w, t}\right)
$$

The quantitative and qualitative effects of this tax revenue-neutral reform are presented in Tables 3.1 and 3.2 (see also Figure 1 in the appendix). In particular, a decrease in second-period income tax rate $\tau_{2}^{y}$ results in an increase in the second-period consumption tax rate. Hence, income taxes are substituted by higher consumption taxes, since the government has to generate the required revenues to finance the provision of public goods, which, as said, is held constant.

Moreover, savings $k_{k, 2}$ are lower. This happens because the savings decision is made in the first period only, where the income tax rate is given. Thus, the introduction of a positive consumption tax in the first period reduces the disposable income of the capitalists and, thus, private consumption and savings. On the other hand, there is a positive effect on savings from the decrease in the second-period income tax rate. However, as the former effect dominates the latter effect, the net effect is a lower capital stock in the second period ${ }^{10}$. Also, labour supply $l_{k, 2}$ increases when second-period income tax falls and consumption tax rises, resulting in higher output and welfare in the economy. Thus, the economy is more efficient as income taxes are substituted by consumption taxes. Also, at an individual level, workers can benefit from a more efficient economy, as can be seen in Table 3.2, where $U_{w}$ has increased. On the other

\footnotetext{
${ }^{9}$ The values that have been assigned to $\tau_{2}^{y}, \tau_{1}^{c}$ and $\tau_{2}^{c}$ are close to OECD averages.

${ }^{10}$ Although we have not managed to establish theoretically why this is the case, we should report that we have experimented with changes in a wide range of parameter values to which this specific result seems to be robust. An exception is the value of the initial income tax rate. In particular, as the initial income tax rate, $\tau_{1}^{y}$, increases, ceteris paribus, it is possible that the positive effect, coming from the lower second period income tax rate, dominates the negative effect, coming from the first period positive consumption tax rate, and thereby savings, $k_{2}$, increase. This is a rather expected result, since the higher the initial income tax rate the lower the need for the government to raise tax revenues through the endogenously determined tax instruments and thereby the less it relies on the use of consumption tax rates which affect negatively - in the first period, through the reduction in the disposable net income the level of savings, $k_{2}$. We would like to thank a referee for highlighting this point.
} 
hand, the welfare of the capitalists $U_{k}$ does not behave monotonically. In particular, it initially increases and then it decreases as $\tau_{2}^{y}$ falls. This happens because high consumption taxes hurt capitalists more. Net income inequality ${ }^{11}$ decreases in the first-period (where the first-period income tax rate is given), while in the second period, net income inequality increases, implying that capitalists' net income $y_{2}^{k}$ increases more than workers' net income $y_{2}^{w}$. Thus, although the substitution of income taxes with consumption taxes is Pareto improving, the associated efficiency gains come at the cost of higher income inequality. This means that there is a tradeoff between efficiency and equity.

The above analysis is for given policy. Next, we move to optimal policy with commitment, the so-called Ramsey equilibrium, in which second-best policy is optimally chosen by a benevolent Ramsey government.

Table 3.1 Decentralized competitive equilibrium

\begin{tabular}{|c|c|c|c|c|}
\hline & $\tau_{2}^{y}=0.4$ & Benchmark & $\tau_{2}^{y}=0.2$ & $\tau_{2}^{y}=0.1$ \\
\hline \hline Allocations & & & & \\
\hline$c_{k, 1}$ & 0.2970 & 0.3000 & 0.3022 & 0.3040 \\
\hline$c_{k, 2}$ & 0.5066 & 0.5077 & 0.5074 & 0.5065 \\
\hline$k_{k, 2}$ & 0.2050 & 0.1967 & 0.1903 & 0.1852 \\
\hline$l_{k, 1}$ & 0.3462 & 0.3414 & 0.3378 & 0.3349 \\
\hline$l_{k, 2}$ & 0.1780 & 0.1908 & 0.2002 & 0.2074 \\
\hline$c_{w, 1}$ & 0.0568 & 0.0569 & 0.0570 & 0.0571 \\
\hline$c_{w, 2}$ & 0.0770 & 0.0784 & 0.0793 & 0.0799 \\
\hline$l_{w, 1}$ & 0.3750 & 0.3750 & 0.3750 & 0.3750 \\
\hline$l_{w, 2}$ & 0.3750 & 0.3750 & 0.3750 & 0.3750 \\
\hline$y_{f, 1}$ & 0.7959 & 0.7908 & 0.7869 & 0.7838 \\
\hline$y_{f, 2}$ & 0.7329 & 0.7492 & 0.7601 & 0.7677 \\
\hline$Y_{1}$ & 0.2388 & 0.2372 & 0.2361 & 0.2351 \\
\hline$Y_{2}$ & 0.2199 & 0.2248 & 0.2280 & 0.2303 \\
\hline$\frac{C_{1}}{Y_{1}}$ & 0.5397 & 0.5474 & 0.5532 & 0.5579 \\
\hline$\frac{C_{2}}{Y_{2}}$ & 0.9366 & 0.9220 & 0.9109 & 0.9025 \\
\hline
\end{tabular}

${ }^{11}$ Notice that net income is defined as: $y_{t}^{k} \equiv\left(1-\tau_{t}^{y}\right)\left(r_{t} k_{k, t}+w_{t}^{k} l_{k, t}\right)-\tau_{t}^{c} c_{k, t}$ for each capitalist and $y_{t}^{w} \equiv\left(1-\tau_{t}^{y}\right)\left(w_{t}^{w} l_{w, t}\right)-\tau_{t}^{c} c_{w, t}$ for each worker. 
ECONOMIDES, RIZOS Optimal Taxation, Efficiency and Redistribution

Table 3.2: Decentralized Competitive Equilibrium

\begin{tabular}{|c|c|c|c|c|}
\hline & $\tau_{2}^{y}=0.4$ & Benchmark & $\tau_{2}^{y}=0.2$ & $\tau_{2}^{y}=0.1$ \\
\hline \hline Policy & & & & \\
\hline$\tau_{1}^{c}$ & 0.2001 & 0.2 (given) & 0.2006 & 0.2007 \\
\hline$\tau_{2}^{c}$ & 0.0717 & 0.2 (given) & 0.3329 & 0.4682 \\
\hline$g_{1}$ & 0.0616 & 0.0616 & 0.0616 & 0.0616 \\
\hline$g_{2}$ & 0.1258 & 0.1258 & 0.1258 & 0.1258 \\
\hline$\frac{g_{1}}{Y_{1}}$ & 0.2580 & 0.2595 & 0.2609 & 0.2620 \\
\hline$\frac{g_{2}}{Y_{2}}$ & 0.5722 & 0.5595 & 0.5517 & 0.5462 \\
\hline$T R 1$ & 0.0616 & 0.0616 & 0.0616 & 0.0616 \\
\hline$T R 2$ & 0.1258 & 0.1258 & 0.1258 & 0.1258 \\
\hline Welfare & & & & \\
\hline$U_{k}$ & -1.7790 & -1.7790 & -1.7794 & -1.7800 \\
\hline$U_{w}$ & -2.9297 & -2.9242 & -2.9206 & -2.9182 \\
\hline$U$ & -2.5845 & -2.5807 & -2.5782 & -2.5767 \\
\hline Net income & & & & \\
\hline$y_{1}^{k}$ & 0.4581 & 0.4527 & 0.4485 & 0.4452 \\
\hline$y_{1}^{w}$ & 0.0568 & 0.0569 & 0.0570 & 0.0571 \\
\hline$y_{2}^{k}$ & 0.3262 & 0.3347 & 0.3399 & 0.3435 \\
\hline$y_{2}^{w}$ & 0.0770 & 0.0784 & 0.0793 & 0.0799 \\
\hline$y_{1}^{k}$ & 8.0664 & 7.9499 & 7.8621 & 7.7924 \\
\hline$y_{1}^{w}$ & & & & \\
\hline$y_{2}^{k}$ & 4.2340 & 4.2668 & 4.2866 & 4.3002 \\
\hline$y_{2}^{w}$ & & & & \\
\hline
\end{tabular}

\subsection{Optimal Policy with Commitment / Ramsey General Equilibrium}

\subsubsection{Results from the Representative Agent Model}

It is useful for what follows to present the numerical results from the respective representative agent model, using the same benchmark parameter values as above. ${ }^{12}$ Thus, we work as follows: Initially, we solve for the commitment equilibrium when the government chooses optimally only the second-period income tax rate. Hence, the government chooses $\tau_{2}^{y}, g_{1}, g_{2}$ to maximize

\footnotetext{
${ }^{12}$ Notice that, in this case, we simply assume that $n^{k}=1, n^{w}=0$ and $\gamma=0$.
} 
the utility of the representative agent subject to the decentralized competitive equilibrium, when we exogenously set $\tau_{1}^{c}=\tau_{2}^{c}=0$. This serves as our benchmark regime. Next, we assume that the government can choose optimally both income and consumption taxes and we solve for two different cases. In the first regime, we introduce a flat consumption tax $\tau^{c}=\tau_{1}^{c}=\tau_{2}^{c}$ that is common in both periods and the government chooses optimally $\tau_{2}^{y}, g_{1}, g_{2}, \tau^{c}$. In the second regime, we assume that the government chooses optimally, among others, two different consumption taxes, one in each period, $\tau_{1}^{c} \neq \tau_{2}^{c}$. A numerical solution for these regimes is presented in Tables 4.1 and 4.2 below.

The main results are the following: There are welfare gains when the government is able to choose optimally both income and consumption taxes. For instance, welfare $U$ and secondperiod output $y_{f, 2}$ are higher with the introduction of consumption taxes. Moreover, the secondperiod net income $Y_{2}{ }^{n}$ of the representative household increases. This happens because the government finds it optimal to raise revenues by setting a positive consumption tax rate. This, ceteris paribus, causes an increase in total tax revenues, creating a fiscal space which allows for a decrease in the more distorting income tax rate in the second period.

Table 4.1: Ramsey Equilibrium / Representative Agent

\begin{tabular}{|c|c|c|c|}
\hline & Benchmark & Flat consumption tax & Consumption taxes \\
\hline & $\tau^{c}=0$ & $\tau^{c} \neq 0$ & $\tau_{1}^{c} \neq \tau_{2}^{c}$ \\
\hline Allocations & & & \\
\hline$c_{1}$ & 0.1317 & 0.0977 & 0.0996 \\
\hline$c_{2}$ & 0.1372 & 0.1281 & 0.1263 \\
\hline$k_{2}$ & 0.0759 & 0.0643 & 0.0623 \\
\hline$l_{1}$ & 0.3429 & 0.3252 & 0.3222 \\
\hline$l_{2}$ & 0.1773 & 0.2237 & 0.2308 \\
\hline$r_{1}$ & 1.1547 & 1.1127 & 1.1055 \\
\hline$r_{2}$ & 0.5431 & 0.7183 & 0.7506 \\
\hline$w_{1}$ & 0.3929 & 0.3992 & 0.4003 \\
\hline$w_{2}$ & 0.5428 & 0.4815 & 0.4725 \\
\hline$y_{f, 1}$ & 0.1925 & 0.1854 & 0.1843 \\
\hline$y_{f, 2}$ & 0.1375 & 0.1539 & 0.1558 \\
\hline$C_{1}$ & 0.6841 & 0.5270 & 0.5405 \\
\hline$Y_{1}$ & & & 0.8110 \\
\hline$C_{2}$ & 0.9983 & 0.8327 & \\
\hline$Y_{2}$ & & & \\
\hline
\end{tabular}


ECONOMIDES, RIZOS Optimal Taxation, Efficiency and Redistribution

Table 4.2: Ramsey Equilibrium / Representative Agent

\begin{tabular}{|c|c|c|c|}
\hline & Benchmark & Flat consumption tax & Consumption taxes \\
\hline \hline $\begin{array}{c}\text { Policy } \\
\text { instruments }\end{array}$ & $\tau^{c}=0$ & $\tau^{c} \neq 0$ & $\tau_{1}^{c} \neq \tau_{2}^{c}$ \\
\hline$\tau_{2}^{y}$ & 0.4878 & 0.1970 & \\
\hline$\tau_{1}^{c}$ & - & - & 0.1208 \\
\hline$\tau_{2}^{c}$ & - & - & 0.3892 \\
\hline$\tau^{c}$ & - & 0.4056 & 0.5177 \\
\hline$g_{1}$ & 0.0289 & 0.0675 & - \\
\hline$g_{2}$ & 0.0671 & 0.0823 & 0.0664 \\
\hline$g_{1}$ & 0.1500 & 0.3638 & 0.0842 \\
\hline$Y_{1}$ & 0.4878 & 0.5348 & 0.3604 \\
\hline$g_{2}$ & & & \\
\hline$Y_{2}$ & -2.6377 & -2.5519 & -2.5509 \\
\hline Welfare outcome & & & \\
\hline$U$ & 0.1636 & 0.1180 & 0.1179 \\
\hline Net income & 0.0704 & 0.0716 & 0.0715 \\
\hline$Y_{1}^{n}$ & & &
\end{tabular}

Also, consumption is lower in both periods due to the high consumption taxes while the lower second-period income tax rate triggers an increase in the second-period labour supply, which, in turn, increases second-period output $y_{f, 2}$. Savings $k_{2}$ are lower with the introduction of the consumption taxes, although the second-period income tax rate $\tau_{2}^{y}$ decreases. This happens because the savings decision about $k_{2}$ is made in the first period, where the income tax rate is given and equal to 0.15 . The introduction of a consumption tax in the first period (or a flat consumption tax that affects both periods) reduces the household's first-period disposable income, which in turn reduces savings $k_{2}$ and consumption $c_{1}$. Thus, there are two opposite effects on savings, where the negative effect from the introduction of the consumption tax rate in the first-period dominates the positive effect from the reduction of the second-period income tax rate. ${ }^{13}$

To sum up, the economy with income and consumption taxes is more efficient than the economy without consumption taxes. In other words, a mix of income and consumption taxes increases welfare and output. Next, we move to the heterogeneous agents' case so as to investigate the distributional implications of the introduction of consumption taxes.

${ }^{13}$ See footnote 10 . 


\subsubsection{Results when Heterogeneity is Allowed}

In this section, our aim is to highlight the aggregate and distributional implications of introducing consumption taxes into a model with income taxes only and heterogeneous agents, when the government chooses optimally the mix of income and consumption taxes. Thus, we choose to work as follows. First, we solve for the Ramsey/commitment equilibrium when the government chooses optimally the second-period income tax rate only. Thus, the government chooses $\tau_{2}^{y}, g_{1}, g_{2}$ to maximize a weighted average of the utilities of the two agents, capitalists and workers, subject to the decentralized equilibrium equations, when we exogenously set $\tau_{1}^{c}=$ $\tau_{2}^{c}=0$. This serves as our benchmark regime. Next, we assume that the government can choose optimally both income and consumption taxes and we solve for two different cases. In the first regime, we introduce a flat consumption tax $\tau^{c}=\tau_{1}^{c}=\tau_{2}^{c}$ that is common for both periods and the government chooses optimally $\tau_{2}^{y}, g_{1}, g_{2}, \tau^{c}$. In the second regime, we assume that the government chooses optimally, among others, two different consumption taxes, one in each period, $\tau_{1}^{c} \neq \tau_{2}^{c}$. A numerical solution for these regimes is presented in Tables 5.1 and 5.2 below.

The main results from the comparison of these regimes are as follows: First, the economy with the consumption taxes is welfare superior to the economy without (benchmark regime). For instance, second-period total output $Y_{2}$ and aggregate welfare $U$ are now higher and this is reasonable since the government has one more policy instrument at its disposal which is less distorting relative to income taxes. Second, at an individual level, both capitalists and workers are better off and benefit from a more efficient economy. For instance, second-period net incomes, $Y_{2}^{k}$ and $Y_{2}^{w}$, and individual welfares, $U^{k}$ and $U^{w}$, are higher when the government is allowed to choose optimally both income and consumption taxes.

Notice that savings $k_{k, 2}$ are lower with the introduction of the consumption taxes. This happens because the saving decision is made by the capitalists in the first period, in which the income tax rate is given. Thus, high positive consumption taxes in the first-period hurt substantially the first-period net income of the capitalists, since $\tau_{1}^{y}$ is given, and, in turn, reduce savings and private consumption. This negative effect on savings dominates the positive effect from the decrease in the second-period income tax rate. Notice here, however, that if we allow for a three period economy where in the second period both the beginning-of-period and the end-of-period capital stock are endogenously determined, the effect of the introduction of consumption taxes on second-period savings $k_{k, 3}$ is positive. Hence, the capital stock in the third period is higher, since the capitalists can benefit from the lower income tax rate in the second period. We present the results for this special case in the appendix. 
ECONOMIDES, RIZOS Optimal Taxation, Efficiency and Redistribution

Table 5.1: Ramsey Equilibrium

\begin{tabular}{|c|c|c|c|}
\hline & Benchmark & Flat consumption tax & Consumption taxes \\
\hline \hline Allocations & $\tau^{c}=0$ & $\tau^{c} \neq 0$ & $\tau_{1}^{c} \neq \tau_{2}^{c}$ \\
\hline$c_{k, 1}$ & 0.3547 & 0.2604 & $0 . .2740$ \\
\hline$c_{k, 2}$ & 0.5156 & 0.5014 & 0.4781 \\
\hline$k_{k, 2}$ & 0.2093 & 0.1883 & 0.1597 \\
\hline$l_{k, 1}$ & 0.3486 & 0.3367 & 0.3206 \\
\hline$l_{k, 2}$ & 0.1713 & 0.2030 & 0.2406 \\
\hline$c_{w, 1}$ & 0.0681 & 0.0491 & 0.0504 \\
\hline$c_{w, 2}$ & 0.0778 & 0.0786 & 0.0787 \\
\hline$l_{w, 1}$ & 0.3750 & 0.3750 & 0.3750 \\
\hline$l_{w, 2}$ & 0.3750 & 0.3750 & 0.3750 \\
\hline$r_{1}$ & 4.7908 & 4.7143 & 4.6104 \\
\hline$r_{2}$ & 1.3168 & 1.5072 & 1.8077 \\
\hline$w_{1}^{k}$ & 1.0675 & 1.0749 & 1.0852 \\
\hline$w_{2}^{k}$ & 1.8568 & 1.7523 & 1.6210 \\
\hline$w_{1}^{w}$ & 0.2135 & 0.2150 & 0.2170 \\
\hline$w_{2}^{w}$ & 0.3714 & 0.3505 & 0.3242 \\
\hline Output $^{w}$ & & & \\
\hline$y_{f, 1}$ & 0.7985 & 0.7857 & 0.7684 \\
\hline$y_{f, 2}$ & 0.7235 & 0.7631 & 0.7937 \\
\hline$Y_{1}=n^{k} y_{f, 1}$ & 0.2395 & 0.2357 & 0.2305 \\
\hline$Y_{2}=n^{k} y_{f, 2}$ & 0.2171 & 0.2289 & 0.2381 \\
\hline$C_{1}$ & 0.6430 & 0.4772 & 0.5096 \\
\hline$Y_{1}$ & & & 0.8337 \\
\hline$C_{2}$ & 0.9634 & 0.8974 & \\
\hline$Y_{2}$ & & & \\
\hline
\end{tabular}

Third, for the regime with the flat consumption tax, the government finds it optimal to set $\tau_{2}^{y}$ at a lower value $(0.1645)$ relative to the case with income taxes only, thereby it chooses to substitute partially the more distorting income tax with the less distorting consumption tax. In other words, the Ramsey government, by realizing that it has a less distorting policy instrument at its disposal, chooses to generate the required revenues to finance the provision of public goods by taxing consumption ( $\tau^{c}=0.3964$ ), so as to mitigate the distortionary effects imposed on the economy by high income taxation. Also, for the regime with the two different 
Review of Economic Analysis 10 (2018) 1-43

Table 5.2: Ramsey Equilibrium

\begin{tabular}{|c|c|c|c|}
\hline & Benchmark & Flat consumption tax & Consumption taxes \\
\hline & $\tau^{c}=0$ & $\tau^{c} \neq 0$ & $\tau_{1}^{c} \neq \tau_{2}^{c}$ \\
\hline Policy instruments & & & \\
\hline$\tau_{2}^{y}$ & 0.4416 & 0.1645 & -1.3471 \\
\hline$\tau_{1}^{c}$ & - & - & 0.3723 \\
\hline$\tau_{2}^{c}$ & - & - & 2.6258 \\
\hline$\tau^{c}$ & - & 0.3964 & - \\
\hline$g_{1}$ & 0.0359 & 0.0799 & 0.0783 \\
\hline$g_{2}$ & 0.1217 & 0.1281 & 0.1324 \\
\hline$g_{1}$ & 0.1500 & 0.3391 & 0.3398 \\
\hline$Y_{1}$ & 0.5605 & 0.5597 & 0.5558 \\
\hline$g_{2}$ & & & \\
\hline Welfare outcome & -1.8331 & -1.7725 & -1.7782 \\
\hline$U_{k}$ & -2.9867 & -2.9126 & -2.9025 \\
\hline$U_{w}$ & -2.6406 & -2.5706 & -2.5652 \\
\hline$U$ & & & \\
\hline Income Inequality & & 8.2479 & 7.7303 \\
\hline$y_{1}^{k}$ & 7.6397 & & 4.2894 \\
\hline$y_{1}^{w}$ & & 4.2682 & \\
\hline$y_{2}^{k}$ & 4.2620 & & 0.3897 \\
\hline$y_{2}^{w}$ & & 0.4048 & 0.0504 \\
\hline$y_{1}^{k}$ & 0.5199 & 0.0491 & 0.3376 \\
\hline$y_{1}^{w}$ & 0.0681 & 0.3356 & \\
\hline$y_{2}^{k}$ & 0.3314 & 0.0786 & \\
\hline$y_{2}^{w}$ & 0.0778 & & \\
\hline & & & \\
\hline
\end{tabular}

consumption taxes, the government chooses a positive consumption tax in the first period $\left(\tau_{1}^{c}=0.3723\right)^{14}$ and an extremely high second-period consumption tax $\left(\tau_{1}^{c}=2.6258\right)$ so as to finance the increased provision of public goods and a very high income subsidy in the second period $\left(\tau_{2}^{y}=-1.3471\right)$. This is a reminiscent of the quite large income subsidy and consumption tax, well in excess of 100\%, in Coleman (2000) and many others. The related

\footnotetext{
${ }^{14}$ First-period income tax rate $\tau_{1}^{y}$ is given and set equal to 0.15 and, therefore, there is no need for the government to offset any distortionary effects. Hence, the government chooses a first-period consumption tax that is lower than $100 \%$, since there is no need to finance an income subsidy and the additional revenues by the consumption tax are used to finance a larger amount of public good $g_{1}$ in the first period.
} 


\section{ECONOMIDES, RIZOS Optimal Taxation, Efficiency and Redistribution}

literature on optimal taxation derives that the optimal tax mix implies the same constant tax rate on consumption and leisure in each period and a zero tax on capital income. Hence, the tax mix that achieves the first best allocation is one that taxes consumption, provides the same amount of subsidy to labour and imposes a zero capital income tax rate (see Lansing (1999), Coleman (2000) and Correia (2010)). The quantitative difference in our results, where the amount of labour subsidy is lower than the amount of the consumption tax, is driven by the fact that we use a single income tax, rather than separate taxes on capital income and labour income. Otherwise, if the Ramsey government can use capital income taxes, labour income taxes and consumption taxes, it could attain the first-best allocation.

Fourth, net income inequality increases when we move from the benchmark regime with income taxes to the regimes where the government chooses optimally both income and consumption taxes. Hence, the reduction in the optimal second-period income tax benefits capitalists more, since they work more, while workers' labour supply is unaffected from changes in the optimal income tax rate. Thus, there is a tradeoff between efficiency and redistribution. Although the introduction of consumption taxes by a Ramsey government is Pareto improving and benefits both capitalists and workers, income inequality increases. The mechanism that drives this result is twofold.

First, a consumption tax alters the savings/consumption decision of the capitalists (see equation 2.5) affecting their income from wealth while there is no income from wealth and such a decision for the workers. Notice that this channel is also present in the representative agent case. Moreover, the degree of substitution between consumption and income taxes in the optimal policy setting with heterogeneous agents determines the nature of the distributional implications of the introduction of consumption taxes in an economy with income taxes only. In our simulations, and for the specific parameter values we have experimented with, this channel leads to higher net income inequality.

Second, the change in capital caused by consumption taxes has differential effects in the income from labour (due to productivity differences), which results to labour income inequality. ${ }^{15}$ However, we should report that our results do not depend on the assumption of different labour productivities among capitalists and workers although in the absence of this differentiation the regressive distributional implications of introducing consumption taxes get weaker. The introduction of consumption taxes in an economy with income taxes only can still be regressive, even in the absence of different labour productivities, as long as, workers are not

\footnotetext{
${ }^{15}$ As explained in section 4, we choose to differentiate labour productivities for two reasons: First, because this assumption is consistent with literature on inequality and especially with that strand of literature that has examined the occupational choice of economic agents, usually focusing on the distinction between entrepreneurs and workers and its implications for skill acquisition (see, e.g., Quadrini 2000; Matsuyama 2006; Kambourov and Manovskii 2009), and second, because it allows us to get a solution for the labour supply of capitalists within accepted range.
} 
allowed to save, or in case they are allowed, they face a higher - than capitalists - transaction cost for participating at the capital market.

Therefore, at least in our numerical simulations, and for the specific parameter values we have used, both the above described channels seem to lead to higher net income inequality. ${ }^{16}$

\subsection{Revenue-Neutral Tax Reforms when Policy is Chosen Optimally}

In this section, we study again the aggregate and distributional implications of introducing consumption taxes into a model with income taxes only, when the government chooses optimally both income and consumption taxes, but we focus mainly on the case in which the overall public spending remains constant and equal to its value when the government chooses optimally only the income tax rate. Thus, we choose to work as follows. First, we solve for the Ramsey/commitment equilibrium when the government chooses optimally the second-period income tax rate only. Thus, the government chooses $\tau_{2}^{y}, g_{1}, g_{2}$ to maximize a weighted average of the utilities of the two agents, capitalists and workers, subject to the decentralized equilibrium equations, when we exogenously set $\tau_{1}^{c}=\tau_{2}^{c}=0$. This serves as our benchmark regime. Next, we assume that the government can choose optimally both income and consumption taxes and we distinguish between two different cases. In the first case, we set $g_{1}, g_{2}$ as in the benchmark regime and allow for the government to choose optimally $\tau_{2}^{y}, \tau_{1}^{c}, \tau_{2}^{c}$. In the second case, we assume that the government chooses optimally all the policy instruments and, particularly, $\tau_{2}^{y}, \tau_{1}^{c}, \tau_{2}^{c}, g_{1}, g_{2}$. Tables 6.1 and 6.2 below present the numerical results for these cases.

A comparison of the above cases reveals the following: The economy with the consumption taxes is welfare superior, even if we keep $g_{1}, g_{2}$ constant. For instance, aggregate welfare $U$ and second-period output $y_{f, 2}$ are higher. At an individual level, workers are better off, since both their welfare $U_{w}$ and their second-period net income $y_{2}^{w}$ are higher. On the contrary, capitalists are worse off when we allow for the government to set the public spending as in the benchmark regime. Notice also that the government chooses to subsidize income and generate the necessary revenues to finance its activity by taxing only consumption. This happens because consumption taxes are less distorting tax instruments than income taxes. Moreover, in terms of inequality, the second-period net income of capitalists relative to workers $\frac{y_{2}^{k}}{y_{2}^{w}}$ increases when the government can choose optimally both income and consumption taxes, even if we keep

\footnotetext{
${ }^{16}$ We would like to thank a referee for highlighting this twofold mechanism which allowed us to make clearer the intuition behind the distributional implications of the introduction of consumption taxes into an economy with income taxes only.
} 
ECONOMIDES, RIZOS Optimal Taxation, Efficiency and Redistribution

Table 6.1: Ramsey Equilibrium

\begin{tabular}{|c|c|c|c|}
\hline & Benchmark & \multicolumn{2}{|c|}{ Consumption taxes } \\
\hline & Endogenous $g_{t}$ & Exogenous $g_{t}$ & Endogenous $g_{t}$ \\
\hline Allocations & & & \\
\hline$c_{k, 1}$ & 0.3547 & 0.3707 & 0.2740 \\
\hline$c_{k, 2}$ & 0.5156 & 0.5079 & 0.4781 \\
\hline$k_{k, 2}$ & 0.2093 & 0.1656 & 0.1597 \\
\hline$l_{k, 1}$ & 0.3486 & 0.3239 & 0.3206 \\
\hline$l_{k, 2}$ & 0.1713 & 0.2333 & 0.2406 \\
\hline$c_{w, 1}$ & 0.0681 & 0.0685 & 0.0504 \\
\hline$c_{w, 2}$ & 0.0778 & 0.0828 & 0.0787 \\
\hline$l_{w, 1}$ & 0.3750 & 0.3750 & 0.3750 \\
\hline$l_{w, 2}$ & 0.3750 & 0.3750 & 0.3750 \\
\hline$r_{1}$ & 4.7908 & 4.6317 & 4.6104 \\
\hline$r_{2}$ & 1.3168 & 1.7409 & 1.8077 \\
\hline$w_{1}^{k}$ & 1.0675 & 1.0831 & 1.0852 \\
\hline$w_{2}^{k}$ & 1.8568 & 1.7409 & 1.6210 \\
\hline$w_{1}^{w}$ & 0.2135 & 0.2166 & 0.2170 \\
\hline$w_{2}^{w}$ & 0.3714 & 0.3295 & 0.3242 \\
\hline Output $_{1,14}$ & & & \\
\hline$y_{f, 1}$ & 0.7985 & 0.7720 & 0.7684 \\
\hline$y_{f, 2}$ & 0.7235 & 0.7895 & 0.7937 \\
\hline$Y_{1}=n^{k} y_{f, 1}$ & 0.2395 & 0.2316 & 0.2305 \\
\hline$Y_{2}=n^{k} y_{f, 2}$ & 0.2171 & 0.2368 & 0.2381 \\
\hline$C_{1}$ & 0.6430 & 0.6875 & 0.5096 \\
\hline$Y_{1}$ & & & 0.8337 \\
\hline$C_{2}$ & 0.9634 & 0.8880 & \\
\hline$Y_{2}$ & & & \\
\hline
\end{tabular}

public spending constant. Hence, the introduction of optimally chosen consumption taxes by a Ramsey government in an economy with income taxes only, increases the aggregate efficiency but also increases net income inequality; even in the case we maintain the level of public spending constant.

\section{A non-utilitarian Ramsey government}

So far we have assumed that the government is utilitarian in the sense that the weights that the government attaches to the welfare of capitalists and workers follow their population shares 
Review of Economic Analysis 10 (2018) 1-43

Table 6.2: Ramsey Equilibrium

\begin{tabular}{|c|c|c|c|}
\hline & Benchmark & \multicolumn{2}{|c|}{ Consumption taxes } \\
\hline & Endogenous $g_{t}$ & Exogenous $g_{t}$ & Endogenous $g_{t}$ \\
\hline \hline Policy instruments & & & \\
\hline$\tau_{2}^{y}$ & 0.4416 & -0.7130 & -1.3471 \\
\hline$\tau_{1}^{c}$ & - & 0.0073 & 0.3723 \\
\hline$\tau_{2}^{c}$ & - & 1.5560 & 2.6258 \\
\hline$g_{1}$ & 0.0359 & 0.0359 & 0.0783 \\
\hline$g_{2}$ & 0.1217 & 0.1217 & 0.1324 \\
\hline$g_{1}$ & 0.1500 & 0.1550 & 0.3398 \\
\hline$Y_{1}$ & 0.5605 & 0.5139 & 0.5558 \\
\hline$g_{2}$ & & & \\
\hline Welfare outcome & -1.8331 & -1.8404 & -1.7782 \\
\hline$U_{k}$ & -2.9867 & -2.9677 & -2.9025 \\
\hline$U_{w}$ & -2.6406 & -2.6296 & -2.5652 \\
\hline$U$ & & & \\
\hline Income Inequality & 7.6397 & 7.1827 & 7.7303 \\
\hline$y_{1}^{k}$ & & & \\
\hline$y_{1}^{w}$ & 4.2620 & 4.3733 & 4.2894 \\
\hline$y_{2}^{k}$ & & & \\
\hline$y_{2}^{w}$ & 0.5199 & 0.4923 & 0.3897 \\
\hline$y_{1}^{k}$ & 0.0681 & 0.0685 & 0.0504 \\
\hline$y_{1}^{w}$ & 0.3314 & 0.3621 & 0.3376 \\
\hline$y_{2}^{k}$ & 0.0778 & 0.0828 & 0.0787 \\
\hline$y_{2}^{w}$ & & & \\
\hline
\end{tabular}

(see e.g. Angelopoulos et al, 2011). But, what will happen if we assume that the government is not utilitarian anymore? This is what we do in this section. In particular, we study the aggregate and distributional implications of introducing consumption taxes when the government is not utilitarian. We present numerical results (see Tables 7.1 and 7.2 respectively) for four cases, namely $\gamma=0.4, \gamma=0.5, \gamma=0.6$, and $\gamma=0.8$. Furthermore, we provide a graph (see figure 1 below) in which the relationship between net income inequality with and without the presence of consumption taxes and $\gamma$ (for $0 \leq \gamma \leq 1$ ) is depicted.

As can be seen in Tables 7.1, 7.2 and Figure 1, our main results remain as the ones analyzed already in the previous sections of the paper. Thus, also when the government is not utilitarian, 
ECONOMIDES, RIZOS Optimal Taxation, Efficiency and Redistribution

Table 7.1: Comparative Static Results with Respect to $\gamma$

\begin{tabular}{|c|c|c|c|c|}
\hline \multicolumn{5}{|c|}{ Only Income Taxes } \\
\hline \hline & $\gamma=0.4$ & $\gamma=0.5$ & $\gamma=0.6$ & $\gamma=0.8$ \\
\hline$c_{k, 1}$ & 0.3539 & 0.3542 & 0.3544 & 0.3549 \\
\hline$c_{k, 2}$ & 0.5056 & 0.5091 & 0.5124 & 0.5186 \\
\hline$k_{k, 2}$ & 0.2109 & 0.2103 & 0.2098 & 0.2088 \\
\hline$l_{k, 1}$ & 0.3495 & 0.3492 & 0.3489 & 0.3483 \\
\hline$l_{k, 2}$ & 0.1685 & 0.1695 & 0.1704 & 0.1721 \\
\hline$c_{w, 1}$ & 0.0680 & 0.0680 & 0.0680 & 0.0681 \\
\hline$c_{w, 2}$ & 0.0760 & 0.0766 & 0.0772 & 0.0783 \\
\hline$l_{w, 1}$ & 0.3750 & 0.3750 & 0.3750 & 0.3750 \\
\hline$l_{w, 2}$ & 0.3750 & 0.3750 & 0.3750 & 0.3750 \\
\hline$Y_{1}=n^{k} y_{f, 1}$ & 0.2399 & 0.2397 & 0.2396 & 0.2394 \\
\hline$Y_{2}=n^{k} y_{f, 2}$ & 0.2159 & 0.2163 & 0.2167 & 0.2174 \\
\hline$\tau_{2}^{y}$ & 0.4568 & 0.4515 & 0.4464 & 0.4369 \\
\hline$g_{1}$ & 0.0360 & 0.0360 & 0.0359 & 0.0359 \\
\hline$g_{2}$ & 0.1255 & 0.1241 & 0.1229 & 0.1205 \\
\hline$U_{k}$ & -1.8324 & -1.8326 & -1.8328 & -1.8333 \\
\hline$U_{w}$ & -2.9873 & -2.9870 & -2.9869 & -2.9866 \\
\hline$U$ & -2.2944 & -2.4098 & -2.5252 & -2.7560 \\
\hline$y_{1}^{k}$ & 7.6581 & 7.6515 & 7.6454 & 7.6342 \\
\hline$y_{1}^{w}$ & & & & 4.2774 \\
\hline$y_{2}^{k}$ & 4.2098 & 4.2284 & 4.2457 & \\
\hline$y_{2}^{w}$ & & & & \\
\hline & & & & \\
\hline
\end{tabular}

consumption taxes seem to create substantial welfare gains for the economy as a whole, whereas, they also seem to increase inequality by hurting the working class. In other words, the efficiency and redistribution effects do not change qualitatively when the government chooses to attach a proportional or less/more proportional weight on the welfare of a specific group (i.e. a $\gamma=$ or $<$ or $>0.5$ ). Moreover, as can be seen in Figure 1, the increase in net income inequality, once we move from an economy with income taxes only to an economy with both income and consumption taxes, gets higher the higher is the weight that the governments attaches to capitalists' welfare. 
Review of Economic Analysis 10 (2018) 1-43

Table 7.2: Comparative static results with respect to $\gamma$

\begin{tabular}{|c|c|c|c|c|}
\hline \multicolumn{5}{|c|}{ Income and Consumption Taxes } \\
\hline \hline & $\gamma=0.4$ & $\gamma=0.5$ & $\gamma=0.6$ & $\gamma=0.8$ \\
\hline$c_{k, 1}$ & 0.2707 & 0.2719 & 0.2730 & 0.2749 \\
\hline$c_{k, 2}$ & 0.4844 & 0.4824 & 0.4803 & 0.4759 \\
\hline$k_{k, 2}$ & 0.1737 & 0.1687 & 0.1641 & 0.1556 \\
\hline$l_{k, 1}$ & 0.3284 & 0.3257 & 0.3231 & 0.3184 \\
\hline$l_{k, 2}$ & 0.2230 & 0.2294 & 0.2352 & 0.2455 \\
\hline$c_{w, 1}$ & 0.0504 & 0.0504 & 0.0504 & 0.0504 \\
\hline$c_{w, 2}$ & 0.0779 & 0.0783 & 0.0785 & 0.0788 \\
\hline$l_{w, 1}$ & 0.3750 & 0.3750 & 0.3750 & 0.3750 \\
\hline$l_{w, 2}$ & 0.3750 & 0.3750 & 0.3750 & 0.3750 \\
\hline$Y_{1}=n^{k} y_{f, 1}$ & 0.2330 & 0.2322 & 0.2313 & 0.2298 \\
\hline$Y_{2}=n^{k} y_{f, 2}$ & 0.2346 & 0.2360 & 0.2372 & 0.2388 \\
\hline$\tau_{2}^{y}$ & -0.2511 & -0.4982 & -0.8406 & -2.1735 \\
\hline$\tau_{1}^{c}$ & 0.3666 & 0.3686 & 0.3705 & 0.3740 \\
\hline$\tau_{2}^{c}$ & 1.0275 & 1.3857 & 1.8847 & 3.8382 \\
\hline$g_{1}$ & 0.0777 & 0.0779 & 0.0781 & 0.0785 \\
\hline$g_{2}$ & 0.1332 & 0.1330 & 0.1327 & 0.1320 \\
\hline$U_{k}$ & -1.7742 & -1.7754 & -1.7768 & -1.7797 \\
\hline$U_{w}$ & -2.9058 & -2.9044 & -2.9033 & -2.9020 \\
\hline$U$ & -2.2269 & -2.3399 & -2.4527 & -2.6776 \\
\hline$y_{1}^{k}$ & 7.9458 & 7.8697 & 7.7980 & 7.6664 \\
\hline$y_{1}^{w}$ & & & & \\
\hline$y_{2}^{k}$ & 4.2546 & 4.2673 & 4.2788 & 4.2991 \\
\hline$y_{2}^{w}$ & & & & \\
\hline & & & & \\
\hline
\end{tabular}

\section{Concluding Remarks}

In this paper, we study the aggregate and distributional implications of introducing consumption taxes into a model with income taxes only, extended to allow for heterogeneity across agents. This heterogeneity is based on the wealth distribution of income. In particular, capitalists are allowed to save while workers are not. The government is allowed to choose optimally a mix of single income and consumption taxes and the associated amount of the provided public good. Notice that we solve for optimal policy with commitment (the so-called Ramsey equilibrium) in which policy instruments are chosen once-and-for all at the beginning of the time horizon. 
Figure 1: Net Income Inequality and $\gamma$

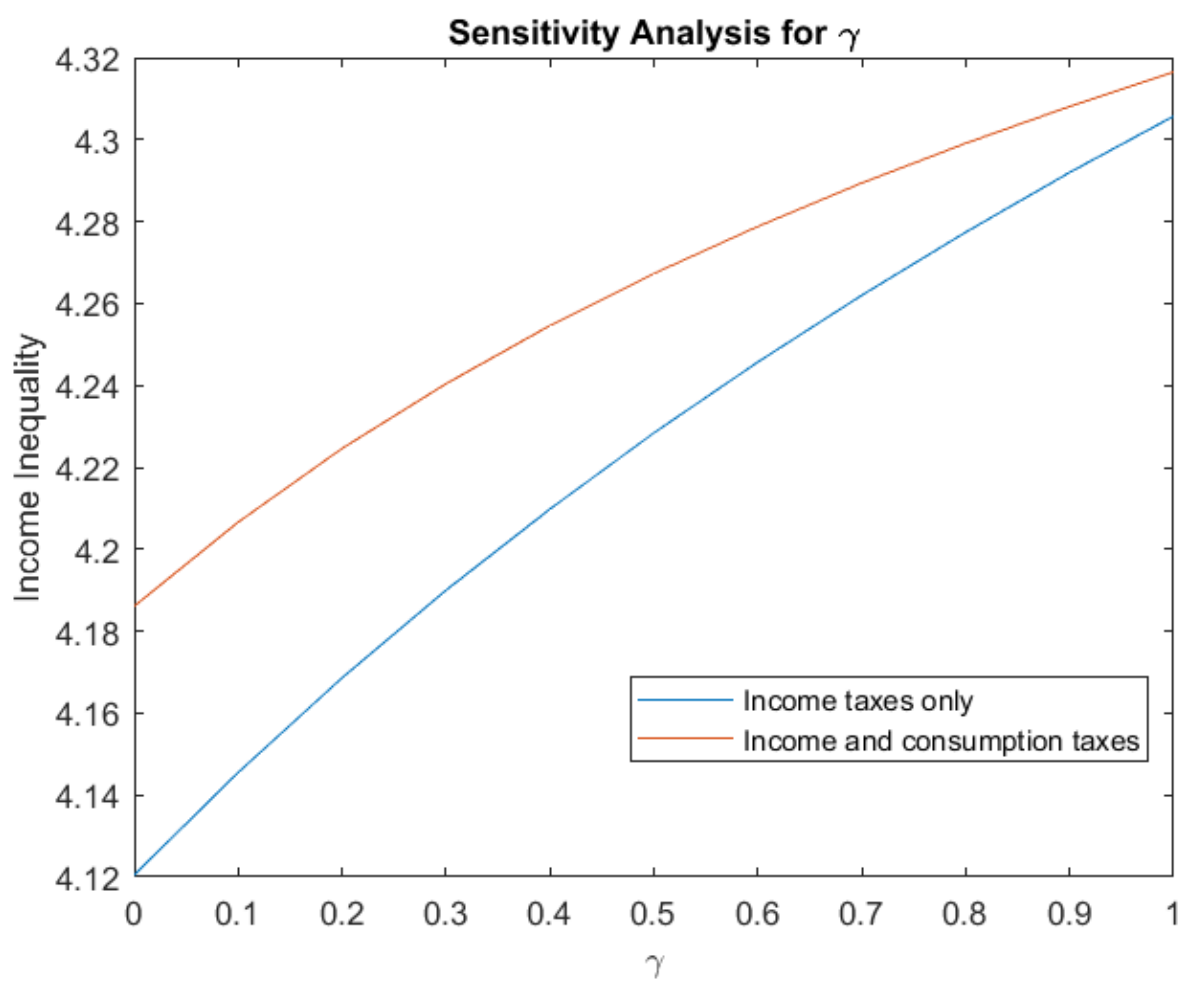

The main theoretical findings can be summarized as follows: Assuming that a benevolent Ramsey government chooses optimally the tax policy mix, consumption taxes turn out to be efficiency enhancing, since they are a less distorting policy instrument. In particular, the government chooses to decrease the second-period income tax rate and generate the required revenues to finance its activities by setting positive consumption taxes. The increased efficiency benefits both groups of households, i.e. capitalists and workers. However, these welfare gains are accompanied by higher inequality, when the latter is measured by the ratio of net incomes. For instance, the net income of capitalists increases by more relative to the net income of workers. Thus, we confirm the widespread belief that the introduction of consumption taxes into a model with income taxes only, creates substantial efficiency gains for the economy as whole, but at the cost of higher net income inequality. Thus, there is a tradeoff between efficiency and redistribution, since the introduction of consumption taxes reduces the progressivity of the tax system. Therefore, from a normative point of view, this may also justify the design of a set of subsidies policies which will aim to outweigh the regressive effects of the otherwise more efficient consumption taxes.

This study can be extended in several ways. For example, one can study the aggregate and distributional implications of introducing consumption taxes in the presence of tax evasion or 
progressive (non-linear) income taxation. Second, one can solve for time-consistent policies and compare them with the commitment / Ramsey equilibrium. We leave these extensions for future work.

\section{References}

Angelopoulos K., J. Malley and A. Philippopoulos (2011): Time-consistent fiscal policy under heterogeneity: conflicting or common interests?, CESifo Working Paper, no. 3444, Munich. Atkinson, A. and J. Stiglitz (1980): Lectures on Public Economics, McGraw Hill, London.

Barro, R.J. (1990): Government spending in a simple model of endogenous growth, Journal of Political Economy, 98, 103-125.

Chamley, C. (1986): Optimal taxation of capital income in general equilibrium with infinite lives, Econometrica, 54, 607-622.

Coleman, W.J. (2000): Welfare and optimum dynamic taxation of consumption and income, Journal of Public Economics, 76, 1-39.

Correia, I. (2010): Consumption taxes and redistribution, American Economic Review, 100, 1673-1694.

Diamond, P. and J. Mirrlees (1971): Optimal taxation and public production I: Production efficiency, The American Economic Review, 61, 8-27.

Drazen, A. (2000): Political Economy in Macroeconomics, Princeton University Press, Princeton, New Jersey.

Economides, G., A. Philippopoulos and V. Vassilatos (2008): The primal versus the dual approach to the optimal Ramsey tax problem, Working Paper.

Economides, G. and A. Philippopoulos (2012): Are user fees really regressive?, CESifo Working Paper, no. 3875, 2012.

Fischer, S. (1980): Dynamic inconsistency, cooperation, and the benevolent dissembling government, Journal of Economic Dynamics and Control, 2, 93-107.

Fowler, S. and E. Young (2006): Uncertainty and fiscal policy, mimeo.

Garcia-Penalosa, C. and S. Turnovsky (2011): Taxation and income distribution dynamics in a neoclassical growth model, Journal of Money, Credit and Banking, 43(8), 1543-1577.

Grossman, G. and E. Helpman (1996): Electoral competition and special interest politics, Review of Economic Studies, 63, 265-286.

Hornstein, A., P. Krussel and G. Violante (2005): The effects of technical change on labour market inequalities, Handbook of Economic Growth, Vol. 1B, Chapter 20.

Jones, L., R. Manuelli and P. Rossi (1993): Optimal taxation in models of endogenous growth, Journal of Political Economy, 101, 485-517.

Judd, K. (1985): Redistributive taxation in a simple perfect foresight model, Journal of Public Economics, 28, 59-83. 
ECONOMIDES, RIZOS Optimal Taxation, Efficiency and Redistribution

Kambourov, G. and I. Manovskii (2009): Occupational specificity of human capital, International Economic Review, 50, 63-115.

Kambourov, G. and I. Manovskii (2009): Occupational mobility and wage inequality, The Review of Economic Studies, 76, 731-759.

King, R. and S. Rebello (1990): Public policy and economics growth: Developing neoclassical implications, Journal of Political Economy, 98, 126-150.

Krusell, P., V. Quadrini and J. Rios-Rull (1996): Are consumption taxes really better than income taxes?, Journal of Monetary Economics, 37(3), 475-503.

Krusell, P. (2002): Time-consistent redistribution, European Economic Review, 46, 755-769.

Lansing, K. (1999): Optimal redistributive capital taxation in a neoclassical growth model, Journal of Public Economics, 73, 423-453.

Laczo S. and R. Rossi (2014): Time-consistent consumption taxation, Working Paper.

Ljungqvist L. and T. Sargent (2004): Recursive Macroeconomic Theory, The MIT Press, second edition, Cambridge, Mass.

Lucas, Jr R.E (1990): Supply-side economics: an analytical review, Oxford Economic Papers, 42, 293-316.

Martin, F. (2010): Markov-perfect capital and labour taxes, Journal of Economic Dynamics and Control, 34, 503-521.

Matsuyama, K. (2006): The 2005 Lawrence R. Klein lecture: Emergent class structure, International Economic Review, 47.2, 327-360.

Milesi-Ferretti, G.M. and N. Roubini (1998): Growth effects of income and consumption taxes, Journal of Money, Credit and Banking, 721-744.

Motta, G and R. Rossi (2015): Optimal fiscal and monetary policy with consumption taxation, Mimeo, Department of Economics, Lancaster University.

Pecorino, P. (1993): Tax structure and growth in a model with human capital, Journal of Public Economics, 52, 251-271.

Persson T. and G. Tabellini (1994): Representative democracy and capital taxation, Journal of Public Economics, 55, 53-70.

Persson T. and G. Tabellini (2000): Political Economics: Explaining Economic Policy, MIT Press, Cambridge, Mass.

Quadrini, V. (2000): Entrepreneurship, saving and social mobility, Review of Economic Dynamics, 3, 1, 1-40.

Rebello, S. (1991): Long-run policy analysis and long-run growth, Journal of Political Economy, 99, 500-521.

Stokey, N. and S. Rebello (1995): Growth effects of flat-rate taxes, Journal of Political Economy, 103, 419-450.

Turnovsky, S. (2000): Methods of Macroeconomic Dynamics, MIT Press, Second edition, Cambridge, Mass. 
Zhang, J., J. Davies, J. Zeng and S. McDonald (2008): Optimal taxation in a growth model with public consumption and home production, Journal of Public Economics, 92(3), 885-896.

\section{A. Appendix}

\section{A.1 First-order Conditions of the Ramsey Government's Problem}

The first-order conditions with respect to allocations $\left\{c_{k, 1}, c_{k, 1}, k_{k, 2}, l_{k, 1}, l_{k, 2}\right\}$ of capitalists, allocations $\left\{c_{w, 1}, c_{w, 2}\right\}$ of workers ${ }^{17}$, prices $\left\{r_{1}, r_{2}, w_{1}^{k}, w_{2}^{k}, w_{1}^{w}, w_{2}^{w}\right\}$ tax instruments $\left\{\tau_{2}^{y}, \tau_{1}^{c}, \tau_{2}^{c}\right\}$ and the Lagrange multipliers $\lambda=1 \ldots 13$, include the following equations:

wrt $c_{k, 1}$ :

$0=(1-\gamma) \frac{\mu_{1}}{c_{k, 1}}+\frac{\mu_{3}}{g_{1}} \tau_{1}^{c} n^{k}-\lambda_{1}\left(1+\tau_{1}^{c}\right)-\lambda_{3} \mu_{2}\left(1+\tau_{1}^{c}\right)+\lambda_{5} \beta\left(1+\tau_{1}^{c}\right)\left[1-\delta+\left(1-\tau_{2}^{y}\right) r_{2}\right]$

wrt $c_{k, 2}$ :

$0=(1-\gamma) \frac{\beta \mu_{1}}{c_{k, 2}}+\beta \frac{\mu_{3}}{g_{2}} \tau_{2}^{c} n^{k}-\beta \lambda_{2}\left(1+\tau_{2}^{c}\right)-\beta \lambda_{4} \mu_{2}\left(1+\tau_{2}^{c}\right)-\lambda_{5}\left(1+\tau_{2}^{c}\right)$

wrt $k_{k, 2}$ :

$$
\begin{aligned}
0 & =\beta \frac{\mu_{3}}{g_{2}} \tau_{2}^{y} n^{k} r_{2}-\lambda_{1}+\beta \lambda_{2}\left\{1-\delta+\left(1-\tau_{2}^{y}\right) r_{2}\right\} \\
& +\beta \lambda_{9}(a-1) a A k_{k, 2}^{a-2}\left(A^{k} l_{k, 2}+A^{w} \frac{n^{w}}{n^{k}} l_{w, 2}\right)^{(1-a)} \\
& +\beta \lambda_{11} a(1-a) A^{k} A k_{k, 2}^{a-1}\left(A^{k} l_{k, 2}+A^{w} \frac{n^{w}}{n^{k}} l_{w, 2}\right)^{(-a)} \\
& +\beta \lambda_{13} a(1 \\
& -a) A^{w} A k_{k, 2}^{a-1}\left(A^{k} l_{k, 2}+A^{w} \frac{n^{w}}{n^{k}} l_{w, 2}\right)^{(-a)}
\end{aligned}
$$

\footnotetext{
${ }^{17}$ Note that we can derive closed-form solutions for the worker's labour supply, given by: $l_{w, 1}=l_{w, 2}=$ $\left(\left(\mu_{1}\right) /\left(\mu_{1}+\mu_{2}\right)\right)$
} 
ECONOMIDES, RIZOS Optimal Taxation, Efficiency and Redistribution

wrt $l_{k, 1}$ :

$$
\begin{aligned}
0=-(1-\gamma) & \frac{\mu_{2}}{1-l_{k, 1}}+\frac{\mu_{3}}{g_{1}} \tau_{1}^{y} n^{k} w_{1}^{k}+\lambda_{1}\left(1-\tau_{1}^{y}\right) w_{1}^{k}-\lambda_{3} \mu_{1}\left(1-\tau_{1}^{y}\right) w_{1}^{k} \\
& +\lambda_{8}(1-a) a A^{k} A k_{k, 1}^{a-1}\left(A^{k} l_{k, 1}+A^{w} \frac{n^{w}}{n^{k}} l_{w, 1}\right)^{(-a)} \\
& +\lambda_{10}(-a)(1-a) A^{k} A k_{k, 1}^{a}\left(A^{k} l_{k, 1}+A^{w} \frac{n^{w}}{n^{k}} l_{w, 1}\right)^{(-a-1)} A^{k} \\
& +\lambda_{12}(-a)(1 \\
& -a) A^{w} A k_{k, 1}^{a}\left(A^{k} l_{k, 1}+A^{w} \frac{n^{w}}{n^{k}} l_{w, 1}\right)^{(-a-1)} A^{k}
\end{aligned}
$$

wrt $l_{k, 2}$ :

$$
\begin{aligned}
0=-(1-\gamma) & \beta \frac{\mu_{2}}{1-l_{k, 2}}+\beta \frac{\mu_{3}}{g_{2}} \tau_{2}^{y} n^{k} w_{2}^{k}+\beta \lambda_{2}\left(1-\tau_{2}^{y}\right) w_{2}^{k}-\beta \lambda_{4} \mu_{1}\left(1-\tau_{2}^{y}\right) w_{2}^{k} \\
& +\beta \lambda_{9}(1-a) a A^{k} A k_{k, 2}^{a-1}\left(A^{k} l_{k, 2}+A^{w} \frac{n^{w}}{n^{k}} l_{w, 2}\right)^{(-a)} \\
& +\beta \lambda_{11}(-a)(1-a) A^{k} A k_{k, 2}^{a}\left(A^{k} l_{k, 2}+A^{w} \frac{n^{w}}{n^{k}} l_{w, 2}\right)^{(-a-1)} A^{k} \\
& +\beta \lambda_{13}(-a)(1 \\
& -a) A^{w} A k_{k, 2}^{a}\left(A^{k} l_{k, 2}+A^{w} \frac{n^{w}}{n^{k}} l_{w, 2}\right)^{(-a-1)} A^{k}
\end{aligned}
$$

wrt $c_{w, 1}$ :

$$
0=\gamma \frac{\mu_{1}}{c_{w, 1}}+\frac{\mu_{3}}{g_{1}} \tau_{1}^{c} n^{w}-\lambda_{6}\left(1+\tau_{1}^{c}\right)
$$

wrt $c_{w, 2}$ :

$$
0=\gamma \beta \frac{\mu_{1}}{c_{w, 2}}+\beta \frac{\mu_{3}}{g_{2}} \tau_{2}^{c} n^{w}-\beta \lambda_{7}\left(1+\tau_{2}^{c}\right)
$$

wrt $r_{1}$ :

$$
0=\frac{\mu_{3}}{g_{1}} \tau_{1}^{y} n^{k} k_{k, 1}+\lambda_{1}\left(1-\tau_{1}^{y}\right) k_{k, 1}-\lambda_{8}
$$


wrt $r_{2}$ :

$0=\beta \frac{\mu_{3}}{g_{2}} \tau_{2}^{y} n^{k} k_{k, 2}+\beta \lambda_{2}\left(1-\tau_{2}^{y}\right) k_{k, 2}+\lambda_{5} \beta c_{k, 1}\left(1+\tau_{1}^{c}\right)\left(1-\tau_{2}^{y}\right)-\beta \lambda_{9}$

wrt $w_{1}^{k}$ :

$$
0=\frac{\mu_{3}}{g_{1}} \tau_{1}^{y} n^{k} l_{k, 1}+\lambda_{1}\left(1-\tau_{1}^{y}\right) l_{k, 1}+\lambda_{3} \mu_{1}\left(1-\tau_{1}^{y}\right)\left(1-l_{k, 1}\right)-\lambda_{10}
$$

wrt $w_{2}^{k}$ :

$0=\beta \frac{\mu_{3}}{g_{2}} \tau_{2}^{y} n^{k} l_{k, 2}+\beta \lambda_{2}\left(1-\tau_{2}^{y}\right) l_{k, 2}+\beta \lambda_{4} \mu_{1}\left(1-\tau_{2}^{y}\right)\left(1-l_{k, 2}\right)-\beta \lambda_{11}$

wrt $w_{1}^{w}$ :

$$
0=\frac{\mu_{3}}{g_{1}} \tau_{1}^{y} n^{w} l_{w, 1}+\lambda_{6}\left(1-\tau_{1}^{y}\right) l_{w, 1}-\lambda_{12}
$$

wrt $w_{2}^{w}$

$$
0=\beta \frac{\mu_{3}}{g_{2}} \tau_{2}^{y} n^{w} l_{w, 2}+\beta \lambda_{7}\left(1-\tau_{2}^{y}\right) l_{w, 2}-\beta \lambda_{13}
$$

$\operatorname{wrt} \tau_{2}^{y}$ :

$$
\begin{aligned}
0=\beta \frac{\mu_{3}}{g_{2}} & {\left[n^{k}\left(r_{2} k_{k, 2}+w_{2}^{k} l_{k, 2}\right)+n^{w} w_{2}^{w} l_{w, 2}\right]-\beta \lambda_{2}\left(r_{2} k_{k, 2}+w_{2}^{k} l_{k, 2}\right) } \\
& -\lambda_{4} \beta \mu_{1} w_{2}^{k}\left(1-l_{k, 2}\right)-\lambda_{5} \beta c_{k, 1}\left(1+\tau_{1}^{c}\right) r_{2} \\
& -\beta \lambda_{7} w_{2}^{w} l_{w, 2}
\end{aligned}
$$

wrt $\tau_{1}^{c}$ :

$$
\begin{gathered}
0=\frac{\mu_{3}}{g_{1}}\left(n^{k} c_{k, 1}+n^{w} c_{w, 1}\right)-\lambda_{1} c_{k, 1}-\lambda_{3} \mu_{2} c_{k, 1}+\lambda_{5} \beta c_{k, 1}\left[1-\delta+\left(1-\tau_{2}^{y}\right) r_{2}\right] \\
-\lambda_{6} c_{w, 1}
\end{gathered}
$$


wrt $\tau_{2}^{c}$ :

$$
0=\beta \frac{\mu_{3}}{g_{2}}\left(n^{k} c_{k, 2}+n^{w} c_{w, 2}\right)-\beta \lambda_{2} c_{k, 2}-\beta \lambda_{4} \mu_{2} c_{k, 2}-\lambda_{5} c_{k, 2}-\beta \lambda_{7} c_{w, 2}
$$

wrt $\lambda_{1}$ :

$$
0=(1-\delta) k_{k, 1}+\left(1-\tau_{1}^{y}\right)\left(r_{1} k_{k, 1}+w_{1}^{k} l_{k, 1}\right)-\left(1+\tau_{1}^{c}\right) c_{k, 1}-k_{k, 2}
$$

wrt $\lambda_{2}$ :

$$
0=\beta\left\{(1-\delta) k_{k, 2}+\left(1-\tau_{2}^{y}\right)\left(r_{2} k_{k, 2}+w_{2}^{k} l_{k, 2}\right)-\left(1+\tau_{2}^{c}\right) c_{k, 2}\right\}
$$

wrt $\lambda_{3}$ :

$$
0=\mu_{1}\left(1-\tau_{1}^{y}\right) w_{1}^{k}\left(1-l_{k, 1}\right)-\mu_{2}\left(1+\tau_{1}^{c}\right) c_{k, 1}
$$

wrt $\lambda_{4}$ :

$$
0=\beta\left\{\mu_{1}\left(1-\tau_{2}^{y}\right) w_{2}^{k}\left(1-l_{k, 2}\right)-\mu_{2}\left(1+\tau_{2}^{c}\right) c_{k, 2}\right\}
$$

wrt $\lambda_{5}$ :

$$
0=\beta\left(1+\tau_{1}^{c}\right) c_{k, 1}\left[1-\delta+\left(1-\tau_{2}^{y}\right) r_{2}\right]-\left(1+\tau_{2}^{c}\right) c_{k, 2}
$$

wrt $\lambda_{6}$ :

$$
0=\left(1-\tau_{1}^{y}\right) w_{1}^{w} l_{w, 1}-\left(1+\tau_{1}^{c}\right) c_{w, 1}
$$

$\operatorname{wrt} \lambda_{7}$ :

$$
0=\beta\left\{\left(1-\tau_{2}^{y}\right) w_{2}^{w} l_{w, 2}-\left(1+\tau_{2}^{c}\right) c_{w, 2}\right\}
$$

wrt $\lambda_{8}$ :

wrt $\lambda_{9}$ :

$$
0=a A k_{k, 1}^{a-1}\left(A^{k} l_{k, 1}+\frac{n^{w}}{n^{k}} A^{w} l_{w, 1}\right)^{1-a}-r_{1}
$$

$$
0=\beta\left\{a A k_{k, 2}^{a-1}\left(A^{k} l_{k, 2}+\frac{n^{w}}{n^{k}} A^{w} l_{w, 2}\right)^{1-a}-r_{2}\right\}
$$


wrt $\lambda_{10}$ :

$$
0=(1-a) A^{k} A k_{k, 1}^{a}\left(A^{k} l_{k, 1}+\frac{n^{w}}{n^{k}} A^{w} l_{w, 1}\right)^{-a}-w_{1}^{k}
$$

wrt $\lambda_{11}$ :

$$
0=\beta\left\{(1-a) A^{k} A k_{k, 2}^{a}\left(A^{k} l_{k, 2}+\frac{n^{w}}{n^{k}} A^{w} l_{w, 2}\right)^{-a}-w_{2}^{k}\right\}
$$

wrt $\lambda_{12}$ :

$$
0=(1-a) A^{w} A k_{k, 1}^{a}\left(A^{k} l_{k, 1}+\frac{n^{w}}{n^{k}} A^{w} l_{w, 1}\right)^{-a}-w_{1}^{w}
$$

wrt $\lambda_{13}$ :

$$
0=\beta\left\{(1-a) A^{w} A k_{k, 2} a\left(A^{k} l_{k, 2}+\frac{n^{w}}{n^{k}} A^{w} l_{w, 2}\right)^{-a}-w_{2}^{w}\right\}
$$

Moreover, for the regime with the flat consumption tax rate, the associated first-order condition is:

wrt $\tau^{c}$ :

$$
\begin{aligned}
0=\frac{\mu_{3}}{g_{1}}\left(n^{k} c_{k, 1}\right. & \left.+n^{w} c_{w, 1}\right)-\lambda_{1} c_{k, 1}-\lambda_{3} \mu_{2} c_{k, 1}+\lambda_{5} \beta c_{k, 1}\left[1-\delta+\left(1-\tau_{2}^{y}\right) r_{2}\right] \\
& -\lambda_{6} c_{w, 1}+\beta \frac{\mu_{3}}{g_{2}}\left(n^{k} c_{k, 2}+n^{w} c_{w, 2}\right)-\beta \lambda_{2} c_{k, 2}-\beta \lambda_{4} \mu_{2} c_{k, 2} \\
& -\lambda_{5} c_{k, 2}-\beta \lambda_{7} c_{w, 2}
\end{aligned}
$$

\section{A.2 A Three Period-Model}

Notice that for the three-period model we assume the same parameter values as in those presented in table 2. We choose to work as follows. First, we solve for the Ramsey/commitment equilibrium when the government chooses optimally the second-period and the third period income tax rates. Thus, the government chooses $\tau_{2}^{y}, \tau_{3}^{y}, g_{1}, g_{2}, g_{3}$ to maximize a weighted average of the utilities of the two agents, capitalists and workers, subject to the decentralized equilibrium equations, when we exogenously set $\tau_{1}^{c}=\tau_{2}^{c}=\tau_{3}^{c}=0$. This serves as our benchmark regime. Next, we assume that the government can choose optimally both income 
ECONOMIDES, RIZOS Optimal Taxation, Efficiency and Redistribution

and consumption taxes and we solve for two different cases. In the first regime, we introduce a flat consumption tax $\tau^{c}=\tau_{1}^{c}=\tau_{2}^{c}=\tau_{3}^{c}$ that is common for all periods and the government chooses optimally $\tau_{2}^{y}, \tau_{3}^{y}, g_{1}, g_{2}, g_{3}, \tau^{c}$. In the second regime, we assume that the government chooses optimally, among others, three different consumption taxes, one in each period, $\tau_{1}^{c} \neq$ $\tau_{2}^{c} \neq \tau_{3}^{c}$. A numerical solution for these regimes is presented in Tables 8.1 and 8.2 below.

Table 8.1: Ramsey Equilibrium - 3 Periods

\begin{tabular}{|c|c|c|c|}
\hline & Benchmark & Flat consumption tax & Consumption taxes \\
\hline & $\tau^{c}=0$ & $\tau^{c} \neq 0$ & $\tau_{1}^{c} \neq \tau_{2}^{c} \neq \tau_{3}^{c}$ \\
\hline Allocations & & & \\
\hline$c_{k, 1}$ & 0.3244 & 0.2336 & 0.2589 \\
\hline$c_{k, 2}$ & 0.5201 & 0.4680 & 0.3918 \\
\hline$c_{k, 3}$ & 0.6156 & 0.6633 & 0.7340 \\
\hline$k_{k, 2}$ & 0.2805 & 0.2536 & 0.2246 \\
\hline$k_{k, 3}$ & 0.3526 & 0.4027 & 0.4625 \\
\hline$l_{k, 1}$ & 0.3903 & 0.3743 & 0.3574 \\
\hline$l_{k, 2}$ & 0.3008 & 0.3130 & 0.3148 \\
\hline$l_{k, 3}$ & 0.1290 & 0.1672 & 0.2177 \\
\hline$c_{w, 1}$ & 0.0655 & 0.0467 & 0.0504 \\
\hline$c_{w, 2}$ & 0.0930 & 0.0852 & 0.0715 \\
\hline$c_{w, 3}$ & 0.0883 & 0.0996 & 0.1173 \\
\hline$l_{w, 1}$ & 0.3750 & 0.3750 & 0.3750 \\
\hline$l_{w, 2}$ & 0.3750 & 0.3750 & 0.3750 \\
\hline$l_{w, 3}$ & 0.3750 & 0.3750 & 0.3750 \\
\hline Output & & & \\
\hline$y_{f, 1}$ & 0.8425 & 0.8258 & 0.8079 \\
\hline$y_{f, 2}$ & 1.0621 & 1.0538 & 1.0192 \\
\hline$y_{f, 3}$ & 0.7416 & 0.8704 & 1.0359 \\
\hline$Y_{1}=n^{k} y_{f, 1}$ & 0.2527 & 0.2477 & 0.2424 \\
\hline$Y_{2}=n^{k} y_{f, 2}$ & 0.3186 & 0.3161 & 0.3058 \\
\hline$Y_{3}=n^{k} y_{f, 3}$ & 0.2225 & 0.2611 & 0.3108 \\
\hline & & & \\
\hline
\end{tabular}


Review of Economic Analysis 10 (2018) 1-43

Table 8.2: Ramsey Equilibrium - 3 Periods

\begin{tabular}{|c|c|c|c|}
\hline & Benchmark & Flat consumption tax & Consumption taxes \\
\hline & $\tau^{c}=0$ & $\tau^{c} \neq 0$ & $\tau_{1}^{c} \neq \tau_{2}^{c} \neq \tau_{3}^{c}$ \\
\hline \multicolumn{4}{|c|}{ Policy instruments } \\
\hline$\tau_{2}^{y}$ & 0.3273 & 0.0805 & -0.3641 \\
\hline$\tau_{3}^{y}$ & 0.4783 & 0.1588 & -1.1535 \\
\hline$\tau_{1}^{c}$ & - & $\begin{array}{l}- \\
\end{array}$ & 0.3447 \\
\hline$\tau_{2}^{c}$ & - & - & 1.4461 \\
\hline$\tau_{3}^{c}$ & - & - & 2.1233 \\
\hline$\tau^{c}$ & - & 0.4371 & - \\
\hline$g_{1}$ & 0.0379 & 0.0821 & 0.0753 \\
\hline$g_{2}$ & 0.1230 & 0.1173 & 0.1117 \\
\hline$g_{3}$ & 0.1407 & 0.1702 & 0.2015 \\
\hline \multicolumn{4}{|c|}{ Welfare } \\
\hline$U_{k}$ & -2.4459 & -2.3911 & -2.3955 \\
\hline$U_{w}$ & -4.0304 & -3.9545 & -3.9379 \\
\hline$U$ & -3.5550 & -3.4855 & -3.4752 \\
\hline \multicolumn{4}{|c|}{ Income Inequality } \\
\hline$\frac{y_{1}^{k}}{y_{1}^{w}}$ & 8.4339 & 9.4961 & 8.7266 \\
\hline$\frac{y_{2}^{k}}{y_{2}^{w}}$ & 6.7303 & 7.6038 & 9.1867 \\
\hline$\frac{y_{3}^{k}}{y_{3}^{w}}$ & 3.4564 & 3.1027 & 2.7884 \\
\hline$y_{1}^{k}$ & 0.5609 & 0.4433 & 0.4394 \\
\hline$y_{1}^{w}$ & 0.0665 & 0.0467 & 0.0504 \\
\hline$y_{2}^{k}$ & 0.6258 & 0.6475 & 0.6567 \\
\hline$y_{2}^{w}$ & 0.0930 & 0.0852 & 0.0715 \\
\hline$y_{3}^{k}$ & 0.3054 & 0.3089 & 0.3271 \\
\hline$y_{3}^{w}$ & 0.0883 & 0.0996 & 0.1173 \\
\hline
\end{tabular}


ECONOMIDES, RIZOS Optimal Taxation, Efficiency and Redistribution

\section{A.3 Figures}

Figure 2: Reforms
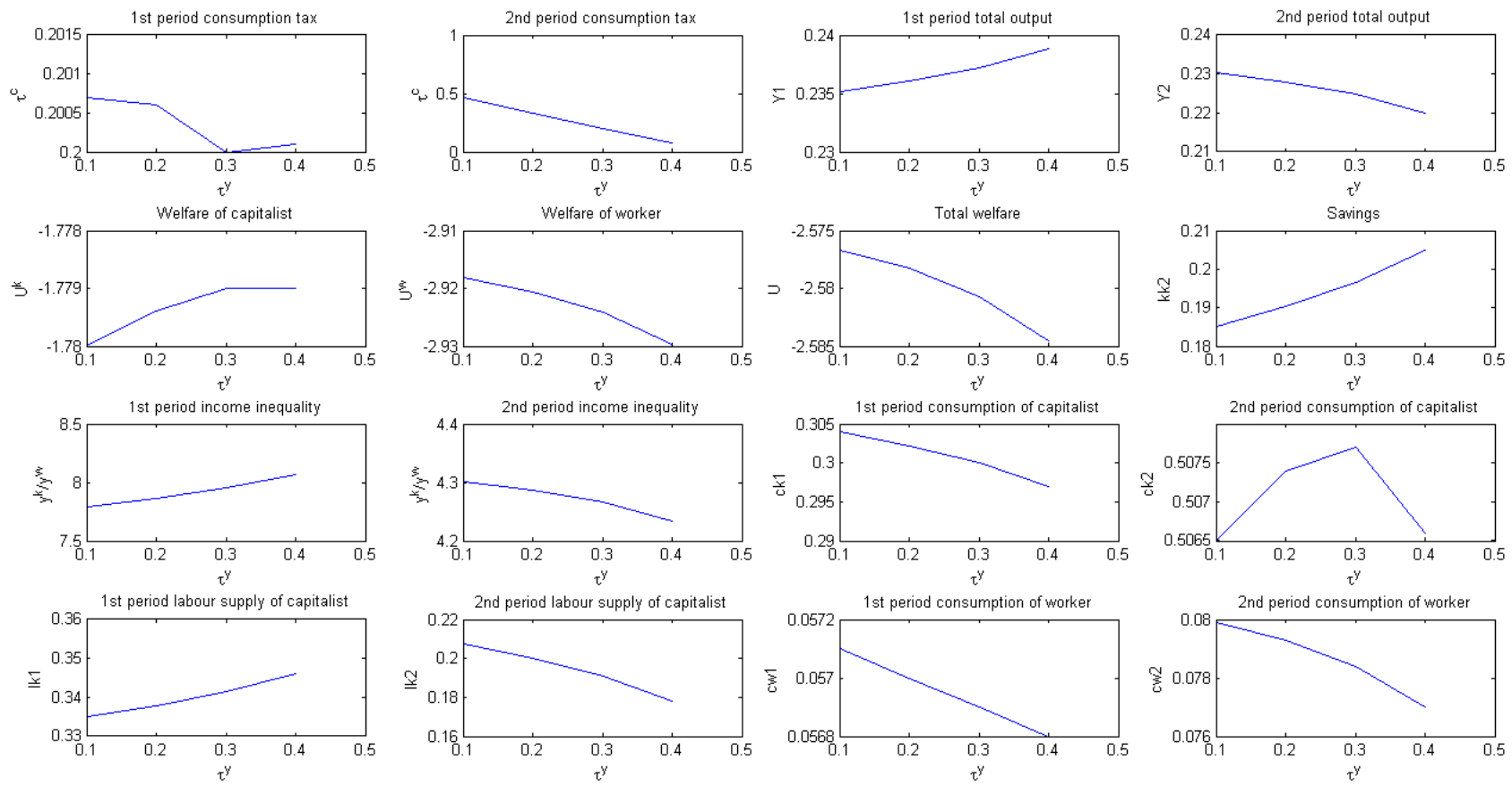